\title{
The Coastal Hazard Wheel system for coastal multi-hazard assessment \& management in a changing climate
}

\author{
Lars Rosendahl Appelquist • Kirsten Halsnæes
}

Received: 19 January 2014 /Revised: 3 March 2015 / Accepted: 4 March 2015 /Published online: 20 March 2015

(C) The Author(s) 2015. This article is published with open access at Springerlink.com

\begin{abstract}
This paper presents the complete Coastal Hazard Wheel (CHW) system, developed for multi-hazardassessment and multi-hazard-management of coastal areas worldwide under a changing climate. The system is designed as a low-tech tool that can be used in areas with limited data availability and institutional capacity and is therefore especially suited for applications in developing countries. The $\mathrm{CHW}$ constitutes a key for determining the characteristics of a particular coastline, its hazard profile and possible management options, and the system can be used for local, regional and national hazard screening and management. The system is developed to assess the main coastal hazards in a single process and covers the hazards of ecosystem disruption, gradual inundation, salt water intrusion, erosion and flooding. The system was initially presented in 2012 and based on a range of test-applications and feedback from coastal experts, the system has been further refined and developed into a complete hazard management tool. This paper therefore covers the coastal classification system used by the CHW, a standardized assessment procedure for implementation of multi-hazard-assessments, technical guidance on hazard management options and project cost examples. The paper thereby aims at providing an introduction to the use of the CHW system for assessing and managing coastal hazards.
\end{abstract}

Keywords Coastal climate change $\cdot$ Hazard assessment . Coastal management · Coastal Hazard Wheel

L. Rosendahl Appelquist $(\square)$

UNEP DTU Partnership, Technical University of Denmark, UN City

Copenhagen, Marmorvej 51, 2100 Copenhagen Ø, Denmark

e-mail: lars.rosendahl@outlook.com

K. Halsnæs

DTU Management Engineering, Technical University of Denmark, Frederiksborgvej 399, 4000 Roskilde, Denmark

\section{Introduction}

This paper presents the Coastal Hazard Wheel (CHW) system that is a tool for combined multi-hazard-assessment and multihazard-management of coastal areas worldwide under a changing climate. The system is developed to address a gap in the current methodologies for coastal hazard assessment and management which generally have high requirements for input data and domain expertise (Ramieri et al. 2011). The system is therefore especially suited for coastal hazard management in developing countries, where data availability and institutional capacity is limited. The system can be used for multi-hazard-assessment and multi-hazard-management at local, regional and national level and covers the hazards of ecosystem disruption, gradual inundation, salt water intrusion, erosion and flooding. It is based on a specially designed coastal classification system that includes 131 different generic coastal environments and a total of 655 individual hazard evaluations, each graduated into four different hazard levels. The initial version of the system was presented in 2012 in the Journal of Coastal Conservation and based on multi-hazardassessments for the Indian state of Karnataka and the African state Djibouti, many spot assessments in locations worldwide and feedback from coastal experts, the system has been refined to a CHW 2.0 version and a standardized application procedure has been developed. This paper therefore presents the refined coastal classification system used in the CHW 2.0, the standardized assessment procedure for implementation of multi-hazard-assessments, guidance on hazard management options for the different coastal environments and cost examples for the management options. As the paper is meant as an overview article, it builds on the previous work on the CHW system and earlier references. The paper should therefore provide an introduction to the main principles and applications of the $\mathrm{CHW}$ system, and interested readers are referred to the related papers for a more detailed description of the theoretical 
basis, practical application, uncertainties and limitations (Rosendahl Appelquist 2012; Rosendahl Appelquist and Balstrøm 2014, 2015).

\section{The coastal classification system}

The coastal classification system constitutes the foundation for the CHW methodology. It is developed particularly for decision-support but includes many components of previously published coastal classification systems. The following sections outline the revised classification system used by the CHW 2.0 and the content is based on the original description published in Rosendahl Appelquist (2012).

The coastal classification system is based on the biogeophysical components that are considered most important for the characteristics of a particular generic coastal environment. The components included are geological layout, wave exposure, tidal range, flora/fauna, sediment balance and storm climate, and each generic coastal environment has a specific combination of these variables. As the bio-geophysical variables can change significantly over short spatial distances, a generic coastal environment will according to the classification system theoretically apply to a particular spot along a coastline. For practical application, however, a generic coastal environment should be considered to extend longshore until any variables included in the system changes significantly.

In order to avoid a disproportionate large number of categories, the system applies an "Any" phrase in cases where a particular classification parameter is of minor importance. Variables such as local isostatic uplift/subsidence and sediment grain size have not been included as these to some extent are indirectly covered through other parameters. This is to achieve an appropriate balance between classification simplicity and correctly reflecting natural conditions. The different classification components have been clearly defined in order to differentiate the generic coastal environments and to make the classification system practical applicable. The definitions and assumptions for the different classification components are outlined below.

\section{Geological layout}

The geological layout constitutes the basis on which the dynamic processes act. It has been created by various past dynamic processes including glacial, fluvial, marine, volcanic and tectonic (Davis and Fitzgerald 2004). The coastal landscape continues to be modified by these processes over different timescales and making an assessment of a particular geological layout will therefore be a snapshot that will change gradually over time. However, as most major changes in geological layout take place on timescales of decades or more, the effect of these changes on the classification is limited.
Furthermore, the subsequent layers in the classification system include the major short-term coastal processes, meaning that most gradual natural changes are handled by the system.

The geological layouts included in the classification system are defined based on a thorough analysis of the world's costal environments and are framed in a way so they cover all major types of geological layouts worldwide. They are defined to include important generic characteristics while still maintaining an appropriate simplicity. The geological layout categories included in the CHW 2.0 are: sedimentary plain; barrier; delta/low estuary island; sloping soft rock coast; flat hard rock coast; sloping hard rock coast; coral island; tidal inlet/sand spit/river mouth. The first four categories are sedimentary geological layouts generally found on trailing edge coastlines such as the Atlantic coast of North- and South America whereas the sloping hard rock coast, is commonly found on leading edge coastlines such as the Pacific coast of North and South America. The flat hard rock coast can appear in various settings e.g. as raised coral reefs, whereas the coral island category is largely depending on tectonic and climatic conditions (Davis and Fitzgerald 2004; Masselink and Hughes 2003). The final category tidal inlet/sand spit/river mouth constitutes a group of specially dynamic geologic environments.

The sedimentary plain category is defined as coasts with average slopes of less than 3-4\% at least $200 \mathrm{~m}$ inland of the MSL, and which are composed of sedimentary deposits such as clay, silt, sand, gravel, till or larger cobbles. If coastal dunes are present, the slope may locally be higher than 3-4\% where the backbeach meets the dunes, but the coast will still fall into the sedimentary plain category. Sedimentary plains are often formed by glacial and fluvial processes or through coastal progradation (Davis and Fitzgerald 2004; Masselink and Hughes 2003).

The barrier category is defined as coasts that consist of non-sloping/low-lying, shore parallel sedimentary bodies with cross distances ranging from less than $100 \mathrm{~m}$ to several kilometres, and lengths ranging from less than $100 \mathrm{~m}$ to over $100 \mathrm{~km}$ (Davis and Fitzgerald 2004). Narrow barriers often exist where the sediment supply is or has been limited, while broad barriers are formed in areas with sediment abundance (Masselink and Hughes 2003). The seaward side of a barrier often contains a wave dominated beach environment, while the landward side consists of protected lagoons and estuaries with various kind of marsh or mangrove vegetation, depending on climatic conditions and tidal range. In meso- and macro-tidal environments, barriers are frequently cut by tidal inlets. In the classification system, a barrier can occur in parallel to coastlines of other geological layouts, located landwards of the barrier. This would e.g. be the case where a sedimentary plain or sloping soft rock coast is located landwards of a barrier.

The delta/low estuary island category is defined as coasts composed of fluvial transported sediment that is deposited in 
front of a river mouth. These landforms form in the coastalfluvial interface where riverine sediment supplied to the coastline is not removed by marine processes. The formation of deltas/low estuary islands is therefore strongly dependent on the fluvial sediment discharge as well as the waves, tides and currents of a particular location. Plate tectonics and regional geological conditions also influence delta formation. Larger deltas are generally found on trailing edge and marginal sea coastlines, where large drainage basins provide a high fluvial discharge, and wide continental shelves provide a relatively shallow depositional area (Schwartz 2005). Small deltas might form along leading edge coastlines but their extension is limited by the smaller drainage basins and steep coastal gradient that does not allow significant sediment accumulation.

The sloping soft rock coast category is defined as coasts comprised of soft rock material with average slopes greater than $3-4 \%$ at least $200 \mathrm{~m}$ inland of the MSL. Coastal cliffs with a steep cliff gradient combined with shore platforms or a landscape flattening landwards of the steep cliff also fall into this category. Sloping soft rock coasts can be comprised of a range of different sedimentary deposits such as chalk, moderately cemented laterite, clay, silt, sand and till with larger pebbles or cobbles. Hard sedimentary rocks are not included in this category and it can therefore be necessary to assess the level of sediment cementation in order to determine whether a particular coast should be classified as soft or hard rock. In the classification system, a rock will fall into the soft rock category if the sediment is poorly cemented, and as a general rule, it should be possible to push a knife some centimetres into the rock material without using excessive force. However, the simplest way to determine whether a coast consists of soft rock material is by using a basic geologic map. Sloping soft rock coasts can exist as both coastal cliffs and gently sloping vegetated hills.

The flat hard rock coast category is defined as coasts consisting of igneous, sedimentary and metamorphic rock with average slopes of less than 3-4\% at least $200 \mathrm{~m}$ inland of the MSL. Igneous rocks are formed from magma and are comprised of a range of different minerals and grain sizes depending on their chemical composition and solidification process. Sedimentary rocks consist of sediment that has undergone different stages of diagenesis, where the sediment has been compacted and cemented under increased temperature and pressure, creating a solid rock structure. Metamorphic rocks have formed from both igneous and sedimentary rocks when they have undergone recrystallization under high temperature and pressure (Press and Siever 2001). The specific physical and chemical rock properties influence the weathering and erosion processes, but for the coastal classification system, hard rock material is considered as one uniform group. Flat hard rock coasts can be present in different forms such as rocky coastal plains, islands and archipelagos.
The sloping hard rock coast category is defined as coasts consisting of igneous, sedimentary or metamorphic rock with average slopes greater than 3-4\% at least $200 \mathrm{~m}$ inland of the MSL. Sloping hard rock coasts can be present in different forms such as coastal mountain chains, headlands and archipelagos.

The coral island category is defined as low-lying coral islands in the form of tropical atolls and coral cays. Tropical atolls are open ocean coral islands that rest on a subsiding volcanic foundation. Atolls have a round shape with diameters ranging from a few kilometres to more than hundred (Schwartz 2005). Coral cays are younger islands formed on top of coral reefs or adjacent to atolls due to the accumulation of reef-derived sediment in one location as result of to wave action. These islands can rise up to three meters above high water level and can be composed of coarse reef fragments or fine carbonate sand. The beaches of both atolls and coral cays can have cemented to form beachrock and coral sandstone that help stabilize the islands (Haslett 2009).

The tidal inlet/sand spit/river mouth category is established as a separate grouping in the classification system as these environments can be highly morphologically active and respond quickly to changes in other coastal processes (Mangor 2004). In the classification system, tidal inlets are defined as the coastline of a tidal inlet itself and one kilometre parallel to the shore on each side of the inlet. Tidal inlets are found along barrier coastlines throughout the world and provide water exchange between an open coast and adjacent lagoons and estuaries. Their morphology depend on a range of different parameters such as tidal range, wave climate and sediment availability (Davis and Fitzgerald 2004). In special cases, where the inlet side consists of a hard rock headland, the inlet side should fall into one of the hard rock categories of the CHW classification system. Sand spits are elongate sedimentary deposits that are formed from longshore currents losing their transport capacity and subsequently depositing sediment at particular locations. They can be present in different shapes and are generally classified into simple linear spits, recurved spits with hook-like appearances, and complex spits with plural hooks (Schwartz 2005). River mouths are defined as the coastline one kilometre on each side of a well defined river mouth. Tidal inlets, sand spits and river mouths are assigned high priority in the $\mathrm{CHW}$ classification system, meaning that e.g. a sedimentary plain will fall into this category if it is located less than one kilometre on each side of a tidal inlet or river mouth.

\section{Wave exposure}

The wave exposure is the dominant energy source in the nearshore environment and a highly important parameter for the coastal morphodynamics. Although some incoming wave energy is reflected by the shoreline, most energy is transformed 
to generate nearshore currents and sediment transport and is a key driver of morphological change (Masselink and Hughes 2003).

For most coastal systems, gravity waves generated by wind stress on the ocean surface are the main source of energy. The restoring force for this wave type is earth's gravity, and gravity waves are generally composed of sea- and swell waves (Masselink and Hughes 2003). Sea waves are formed under direct influence of the wind on the ocean surface and have peaked crests and broad troughs. They are often complicated with multiple superimposed sets of different wave sizes and whitecaps can be present during high wind speeds. Swell waves develop after the wind stops and where the waves travel outside the area where the wind is blowing. They have a sinusoidal shape and commonly have long wavelengths and small wave heights (Masselink and Hughes 2003). The wave height is the generally applied measure for incoming wave energy and is defined as the difference in elevation between the wave crest and wave trough (Davis and Fitzgerald 2004). Since the wave energy increases as the square of the wave height, coastal environments with high wave heights have relatively high energy intensity compared to protected coasts (Thieler et al. 2000).

The coastal classification system distinguishes between exposed, moderately exposed and protected coastlines. The distinction between these categories is based on the significant wave height, $\mathrm{H}_{\mathrm{S}}$, that represents the average wave height of the one-third highest waves in a wave record and corresponds well to the visual wave height estimates (Masselink and Hughes 2003). To ensure consistency, the classification system uses the $\mathrm{H}_{\mathrm{S}} 12 \mathrm{~h} / \mathrm{yr}$, which is the nearshore significant wave height exceeded for $12 \mathrm{~h}$ per year (Mangor 2004).

The wave exposure level is determined based on the coastline geography and wind climate. All coastlines located in areas with swell waves are in the classification system defined as moderately exposed (Mangor 2004). These coastlines can be indentified based on Fig. 1, where coasts falling into "West coast swell", "East coast swell" and "Trade/monsoon influences" are categorized as moderately exposed coastlines. It should be noted, however, that backbarrier and inner estuary coastlines in these regions are not swell wave coasts.

If the coastline is located outside the swell regions, the wave exposure should ideally be determined based on the SB-M method. This method uses a nomogram to predict $\mathrm{H}_{\mathrm{S}}$ by input of wind speed, wind duration and fetch length and the nomogram is included in the paper for the CHW 1.0 (Rosendahl Appelquist 2012; Coastal Engineering Research Center 1984). If the $\mathrm{H}_{\mathrm{S}} 12 \mathrm{~h} / \mathrm{yr}$ is determined as more than $3 \mathrm{~m}$, the coast is considered exposed, while it is considered moderately exposed with an $\mathrm{H}_{\mathrm{S}} 12 \mathrm{~h} / \mathrm{yr}$ of 1-3 m. If the $\mathrm{H}_{\mathrm{S}}$ $12 \mathrm{~h} / \mathrm{yr}$ is determined as less than $1 \mathrm{~m}$, the coast is considered to be protected.
Since it in many cases can be difficult to obtain the necessary wind data to apply the S-B-M method, the free fetch can be used to roughly estimate the exposure levels of non-swell coastlines. This is therefore the standard methodology applied in the CHW system. Coasts can be considered exposed if they border waterbodies larger than $100 \mathrm{~km}$, while they can be considered moderately exposed if they are associated with waterbodies of the size of approximately $10-100 \mathrm{~km}$. Protected coasts are generally restricted to inner waterbodies in the order of less than $10 \mathrm{~km}$, but can also be seen along larger waterbodies with shallow nearshore zones or mild onshore wind climates (Mangor 2004). When estimating the exposure levels, it is therefore important to be aware of physical conditions such as coastal reefs, tidal flats or wind conditions that cause the coast to fall into the protected category even when the water body is larger than $10 \mathrm{~km}$. Ice affected coastlines may have seasonal fluctuating wave exposures due to presence of winter sea ice. As sea ice is expected to be highly vulnerable to climate change, however, the same approach as for ice free coasts should be applied. Only in locations where the sea ice is expected to be very stable, the fetch length has to take into account the ice cover.

\section{Tidal range}

Tides can have major impact on shoreline processes and on the development of coastal landforms. They are a manifestation of the moon's and sun's gravitational force acting on earth's hydrosphere and are present in the form of oceanic waves with wavelengths of thousands kilometres, resulting in periodic fluctuations in coastal water levels (Davis and Fitzgerald 2004). Tides fluctuate on a daily basis following diurnal, semidiurnal and mixed tidal cycles (Davis and Fitzgerald 2004). Diurnal tides exhibit one tidal cycle daily whereas semidiurnal tides exhibits two cycles daily. Mixed tides have components of both diurnal and semidiurnal tides varying throughout the lunar cycle (Davis and Fitzgerald 2004). Globally, semidiurnal and mixed tides are dominating coastal areas (Haslett 2009).

From a morphodynamic perspective, the tidal range influences coastal processes in many ways and is controlling the horizontal extent of the intertidal zone, the vertical distance over which coastal processes operate and the area being exposed and submerged during a tidal cycle (Haslett 2009). The tidal range is defined as the height difference between the high water and low water during a tidal cycle (Schwartz 2005) and the tidal range of a particular coastal location is controlled by a range of different parameters including the distance from an oceanic amphidromic point, the local bathymetry, the width of the continental shelf and the coastal configuration (Haslett 2009). The numerical value of the tidal range vary significantly between coastal locations and span from almost zero to about $16 \mathrm{~m}$ in funnel shaped embayments such as the Bay of 
Fig. 1 Global wave climates (Davies 1980, modified by Masselink and Hughes 2003)

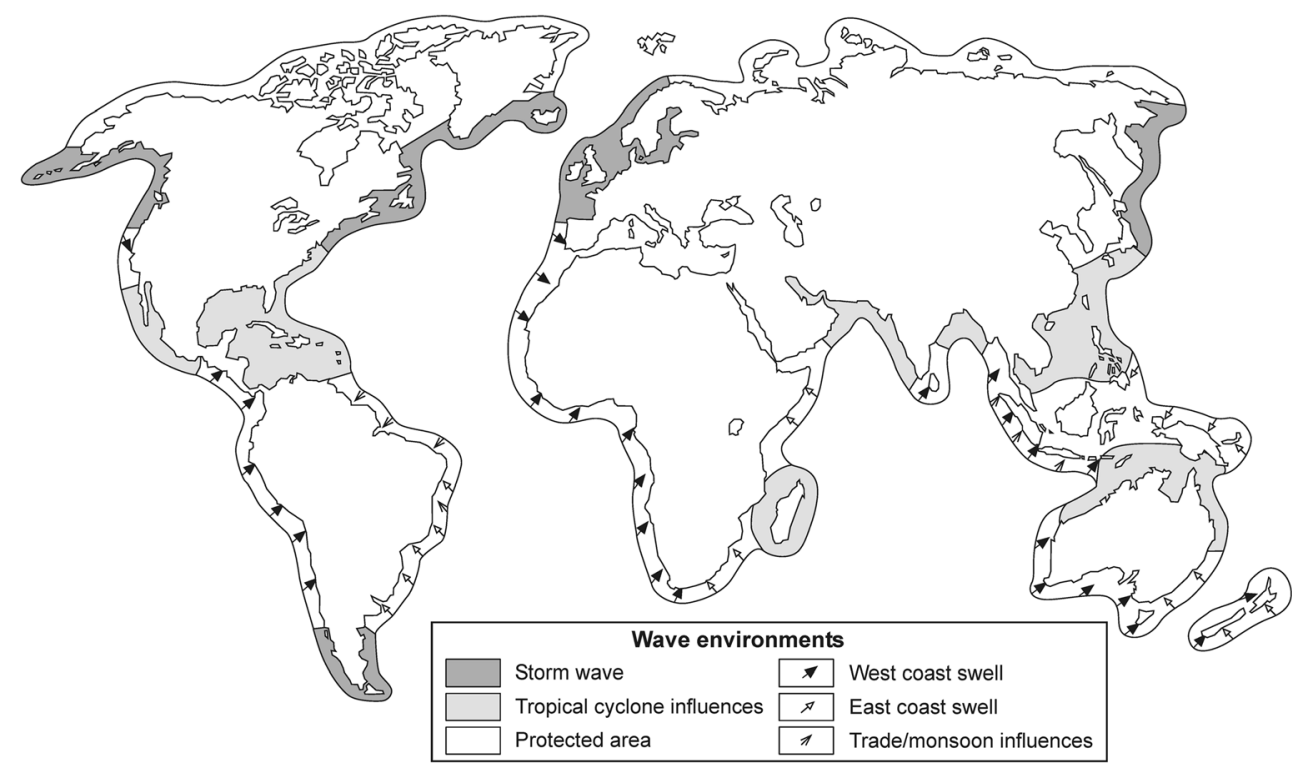

Fundy, Canada (Davis and Fitzgerald 2004). Tides of a particular location also fluctuate on a daily basis depending on planetary positions.

For classification purposes, coastlines can be grouped into various tidal environments based on tidal range, and a generally used classification system operates with the three main categories micro-tidal, meso-tidal and macro-tidal (Schwartz 2005). Micro-tidal environments are defined as coasts where the tidal range does not exceed $2 \mathrm{~m}$ and can be found on open ocean coastlines such as the eastern seaboard of Australia and the majority of the African Atlantic coast (Haslett 2009). Meso-tidal environments are defined as coasts with a tidal range of 2-4 $\mathrm{m}$ and examples of these are found on the Malaysian and Indonesian coasts and on the eastern seaboard of Africa (Haslett 2009). Macro-tidal environments are defined as coasts where the tidal range exceeds $4 \mathrm{~m}$ which is the case along some of the northwest-European coasts and in parts of north-eastern North America (Haslett 2009). The global distribution of micro-, meso- and macro-tidal environments is shown in Fig. 2.

The effect of tidal range on coastal morphodynamics is largely influenced by the local wave conditions. Therefore, the relative size of tides and waves of a particular location is - seen from a morphodynamic perspective - more important than the magnitude of the tidal range itself (Masselink and Hughes 2003). This relationship is illustrated by the relative tidal range expression that states that the relative morphodynamic importance of the tidal range decreases with increasing wave exposure (Masselink and Hughes 2003). This principle is applied in the classification system that uses the three different tidal categories, micro, meso/macro and any that are applied in accordance with wave exposure. Where the coastline is exposed or moderately exposed, the classification uses the any tide category as these environments are considered to be largely dominated by wave processes. This may lead to some inaccuracies in the hazard assessment of coastlines with a very large tidal range but is considered a reasonable simplification taking the impacts of other classification parameters into account. At protected coastlines, the tidal range can have major impact on the coastal morphodynamics and the classification system therefore distinguishes between micro and meso/macro-tidal conditions. Under micro-tidal conditions, these coastlines will still be partly wave dominated whereas they will be largely tide dominated under meso/macro-tidal conditions. The merging of meso/macro tides is regarded as an acceptable simplification without major implications for a reliable hazard evaluation, except under extreme high tidal range conditions. Since the effect of tidal range on the inherent hazards of sloping soft rock coasts, flat hard rock coasts, sloping hard rock coasts and coral islands is considered to be minor, the any tide category has been applied to these layouts for simplification purposes. In the case of tidal inlets, tidal forces play a key role for their morphodynamics, but these environments are included in a separate category due to their special properties.

\section{Flora/fauna}

For some coastal environments, the local flora/fauna constitutes an important parameter for their morphodynamics and inherent climate change hazards. In the classification system, the flora/fauna has been included where it is considered to play an important role for the characteristics and inherent hazard profile of a coastal environment. The integration of the flora/fauna component in the classification system is complicated by its interdependence with other physical classification parameters and this is reflected in the application of the flora/ fauna categories. In total, the classification system operates 
Fig. 2 Map over global variation in tidal range (Davies 1980, modified by Masselink and Hughes 2003)

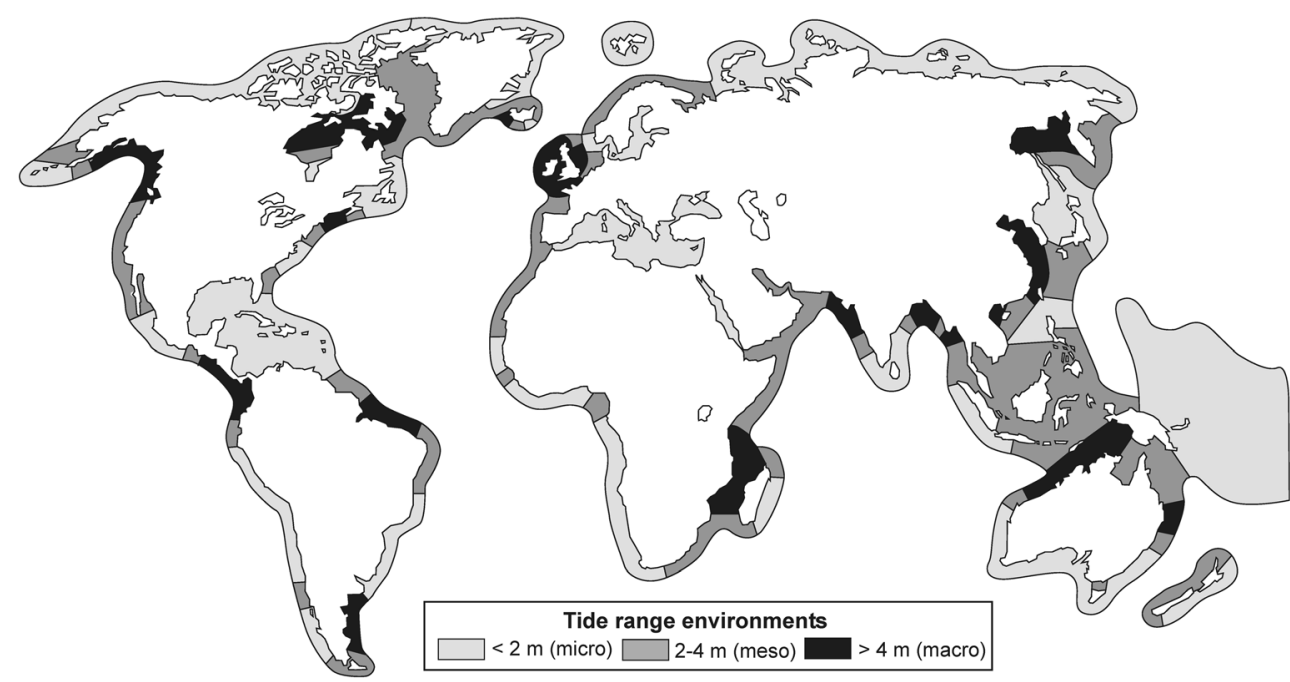

with nine different categories namely intermittent marsh; intermittent mangrove; marsh/tidal flat; mangrove; marsh/ mangrove; vegetated; not vegetated; coral and any.

The intermittent marsh and marsh/tidal flat categories are applied to coastlines whose geological layout falls into the categories sedimentary plain, barrier and deltallow estuary island. The marsh is a grass-like vegetation of salty and brackish areas along protected, low energy coastlines. It colonizes higher parts of the intertidal environment, forming coastal wetlands that act as a sediment trap for fine grained sediment. Marsh areas gradually build up from continuous flooding and subsequent sediment deposition, which can be particularly large during storm events. Due to the continuous accumulation of sediment, marsh areas can to some degree follow sea level rise but will eventually drown if sea level rises too rapidly. In locations with a high tidal range, marsh areas are often continuous and combined with extensive tidal flats, and the classification therefore distinguishes between the intermittent marsh category applied to areas with micro-tidal conditions and the marsh/tidal flat category applied to areas with meso/ macro-tides.

The intermittent mangrove and mangrove categories are applied to coastlines falling into the geological layout categories sedimentary plain, barrier and delta/low estuary island. Mangrove is a woody shrub vegetation that grows along protected, low energy coastlines forming a swampy environment. It is very dependent on air temperature and cannot tolerate a freeze and its geographical extension is therefore limited to low and moderate latitudes. The extensive root network of mangroves acts as an efficient trap for fine grained sediment and reduces wave erosion of the coastline. Like marsh areas, mangrove forests are rich ecosystems providing nursing grounds for many animals and in addition limit erosion and flooding from tropical storms. In the classification system, the intermittent mangrove category is applied to areas with microtidal conditions, while the mangrove category is applied to areas with meso/macro-tides, as they colonise the tidal flats. The combined marsh/mangrove category is applied to protected, flat hard rock coasts that have a narrow band of marsh/mangrove vegetation.

The vegetated and not vegetated categories are applied to the geological layout category sloping soft rock coast where vegetation of the coastal slopes plays an important role for the coastline characteristics. The vegetated category is applied when more than $25 \%$ of the slope is covered with vegetation while the not vegetated category is used when less than $25 \%$ is vegetated. Possible vegetation includes different grasses, scrubs and trees depending on the soft rock properties, slope and climatic conditions. Although some types of vegetation have a better stabilizing effect than others, the important criteria seen from a coastal classification perspective is whether the coastal slope is vegetated or not. Sloping soft rock coasts may be fronted by a narrow band of marsh or mangrove vegetation but this is not considered of major importance from an inherent hazard perspective. In cases where the fronting marsh or mangrove areas are more extensive, the coastline will automatically fall into one of the non-sloping geological layout categories.

The coral category is applied to flat hard rock coasts and sloping hard coasts where the corals have a firm substrate to thrive on. Corals are carnivorous suspension feeders, living in large colonies as polyps with an external skeleton of calcium carbonate (Masselink and Hughes 2003). Since they generally attach to hard substrates, rocky shorelines provide suitable coral habitats (Masselink and Hughes 2003). Reef building coral species only thrive in water temperatures between 18 and $34{ }^{\circ} \mathrm{C}$ and are thus limited to tropical and subtropical environments (Davis and Fitzgerald 2004). Reef building corals are very light sensitive and reefs are rarely being created at depths greater than $50 \mathrm{~m}$. Locally, water turbidity and salinity can be important parameters for reef formation, and high turbidity can decrease light penetration and increase 
sedimentation, thereby inhibiting coral growth. Salinity levels outside the range of $27-40 \mathrm{ppt}$ also limit reef formation, and low salinity combined with high turbidity often explain the reef openings found close to river mouths (Masselink and Hughes 2003). Corals can survive in high energy wave environments and even shows enhanced growth on exposed coastlines (Masselink and Hughes 2003). In the classification system, the coral category includes both fringing and barrier reefs fronting rocky coastlines. Since coral reefs often are backed by carbonate beaches and not bare rock, the special beach category available in the classification system for flat hard rock coasts and sloping hard coasts captures this condition. The separate geological layout category for coral islands is assumed to be associated with coral reef environments of various kinds.

The any category (also indicated with an $A$ in the CHW) is used when the flora/fauna is not considered to play an important role for the coastal characteristics and/or inherent hazard profile. In some cases, the flora/fauna may have relevant functions such as the ability of lyme grasses to reduce aeolian sediment transport, but compared to the other classification parameters it is not expected to influence the included hazards significantly.

\section{Sediment balance}

The sediment balance is an essential morphodynamic parameter and particularly important for coastlines falling into the sedimentary layout categories. The sediment balance determines whether there is a net accumulation, removal or balance of sediment at a particular coastline over time and is largely determined by the sediment transport and availability.

The coastal sediment transport can be divided into two main categories, namely transport of non-cohesive and cohesive sediment. Transport of non-cohesive, sand-sized sediment, termed littoral transport, plays an essential role for the sediment balance of exposed and moderately exposed sedimentary coastlines. This type of transport is mainly controlled by the wave height, wave incidence angle and sediment grain size, and large quantities of sediment can be transported down the coastline by this process (Mangor 2004; Davis and Fitzgerald 2004). Coastlines dominated by littoral sediment transport generally respond to physical changes by adjusting their theoretical equilibrium profile, which is the average characteristic form of a coastal profile, controlled by sediment grain size and to some degree wave conditions. Changes in sediment availability, storm conditions or sea level will cause the theoretical equilibrium profile to shift to a new equilibrium state that matches the changing framework conditions. Because of this mechanism, a coastal profile will require more sand to maintain its existing shoreline position if a new equilibrium profile is created due to sea level rise. This will lead to shoreline erosion if no net sediment supply is present.
Transport of fine, cohesive sediment or mud plays an important role in the sediment balance of protected coastal areas. Cohesive sediment particles have a relatively low fall velocity compared to sand grains and the individual grains have the ability to cohere to each other. These particles cannot form stable coastal profiles in exposed and moderately exposed coastlines since they easily go into suspension. Fine grained, muddy coasts are therefore only found in protected coastal areas where there is abundance of cohesive sediment. Such coastlines are generally vegetated with marsh or mangrove vegetation, sometimes combined with mud/tidal flats (Mangor 2004). Coastlines dominated by cohesive sediment can respond to rising sea level by growing vertically by increasing the sediment accumulation rate, but may also suffer from inundation and erosion depending on sediment availability and tidal dynamics.

In the classification system, the sediment balance section includes the two main categories balance/deficit and surplus and the two special categories no beach and beach that applies to the hard rock coastlines. It has been decided to group the balance/deficit categories together to simplify the classification system and to ease the difficult evaluation of the sediment balance on-site or remotely. Coastal areas that are currently experiencing sediment deficits or only have sufficient sediment to remain stable at current conditions are likely to suffer from sediment deficits with a rising sea level, unless new sediment sources emerge (Haslett 2009). Coastal areas that currently experience sediment surplus might suffer deficits at a later stage if sea level rises sufficiently or there is a change in local sediment dynamics. However, seen from a hazard perspective, these coastlines are less likely to experience severe sediment deficits in the near future.

For achieving an optimal accuracy of the hazard assessment, temporal data on sediment transport, erosion and accumulation would be valuable for determining the sediment balance of a particular coastline. As the CHW system is intended to be used in areas with limited data availability, however, it is designed to rely on a combination of remote sensing data and on-site assessments. Direct short-term observations are complicated by the fact that single storm and high-wave events can lead to temporal coastline erosion which is reversed during calm conditions, thus causing fluctuating erosion and accumulation patterns (Mangor 2004; Stive et al. 2002). This means that a particular coastal area may one day appear to erode while looking stable sometime later. For evaluation of the sediment balance, it is therefore recommended to make use temporal remote sensing techniques to evaluate coastal changes over several years. In case there is any doubt about the sediment balance evaluation, the user should assume a balance/deficit as this is the default category for the CHW system. This is also recommended where there are indications of short-term human alteration of the sediment balance.

For hard rock coastlines, the classification system does not require a sediment balance evaluation but simply apply a no 
beach category if the coast consists of bare rock and a beach category if some kind of beach environment is present.

\section{Storm climate}

In areas with tropical cyclones, coastal areas can experience extreme wind, wave, and precipitation conditions that significantly affect the coastal morphodynamics and inherent hazard profile. Tropical cyclones are generated over tropical seas where the water temperature exceeds $27^{\circ} \mathrm{C}$. They are normally generated between $5^{\circ}-15^{\circ} \mathrm{N}$ and $5^{\circ}-15^{\circ} \mathrm{S}$ and about 60 tropical cyclones are generated annually worldwide with peak periods in September in the Northern Hemisphere and in January in the Southern Hemisphere (Mangor 2004). Wind speeds in tropical cyclones exceed $32 \mathrm{~m} / \mathrm{s}$ and can cause extreme wave heights, storm surges and cloudburst. Although tropical cyclones have a great impact on the coastal morphology when they hit, the general coastal morphology of an area is largely determined by the local wave climate (Mangor 2004).

The classification system distinguishes between locations with and without tropical cyclone activity, without considering their frequency. This is decided as tropical cyclones contribute to the inherent hazards in all areas where they occur regardless of their frequency. The classification system uses the map shown earlier in Fig. 1 to categorize the influence of tropical cyclones on coastal areas (Masselink and Hughes 2003). In areas indicated to be under "Tropical cyclone influence" the classification system applies a yes to tropical cyclone activity while it applies a no for locations outside these areas.

\section{The inherent hazard levels}

The hazards included in the CHW system are defined as the hazards being an inherent part of the bio-geophysical properties of a coastal environment when exposed to the predicted changes in global climate over the coming decades (IPCC 2007, 2013). The inherent hazards covered by the CHW system are ecosystem disruption, gradual inundation, salt water intrusion, erosion and flooding, which describe the following.

- The inherent hazard for ecosystem disruption describes the possibility of a disruption of the current state of the coastal ecosystems under a changing climate.

- The inherent hazard for gradual inundation describes the possibility of a gradual submergence of a coastal environment under a changing climate.

- The inherent hazard for salt water intrusion describes the possibility of salty sea water penetrating into coastal surface waters and groundwater aquifers under a changing climate.
- The inherent hazard for erosion describes the possibility of erosion of a coastal environment under a changing climate.

- The inherent hazard for flooding describes the possibility of a sudden, abrupt and often dramatic inundation of a coastal environment caused by a short term increase in water level due to storm surge and extreme tides, under a changing climate.

The hazard levels of the CHW are based on a scientific literature review of the characteristics of the world's coastal environments and their susceptibility to climate-related parameters. The hazard levels should be seen as the hazard presence in a particular coastal environment in the coming decades. Since this approach is surrounded by some uncertainty, the hazard graduation simply distinguishes between four different hazard levels, depending on the hazard presence. It is believed that the four-grade system provides sufficient information to be relevant for decision-support, while at the same time appropriately reflecting the uncertainties associated with the hazard graduation methodology. The four levels included are defined so that 4 equals very high hazard presence, 3 equals high hazard presence, 2 equals moderate hazard presence and 1 equals low hazard presence. Each generic coastal environment has been assigned a specific inherent hazard level for each of the hazard types, and in the CHW, the graduation is displayed as a combined number/colour code to give the user the best possible overview of the hazard profile of a particular coastal environment. A total of 655 individual hazard evaluations are assigned to the 131 different coastal environments of the CHW 2.0 version. For an elaborate description of the basis for the assigned hazard levels, the reader is referred to the background paper for the CHW 1.0. The hazard values for the revised/new hard rock coast categories of the CHW 2.0 are based on the values for the coastal plain and sloping hard rock coast categories of the CHW 1.0 (Rosendahl Appelquist 2012). The revised CHW 2.0 is shown in Fig. 3, and is used by starting in the wheel centre and moving outwards, ending with the hazard evaluation in the outermost circles.

\section{Application for multi-hazard-assessments}

The CHW system can be applied for coastal multi-hazardassessments at local, regional and national level, and for spot-assessments to indentify the hazard profile and management options for a particular coastal site. Depending on the data availability and accuracy requirements, the CHW can be applied at three different assessment steps, namely:

- Step 1 that is designed for hazard assessments where data availability and accuracy requirements are relatively low. 


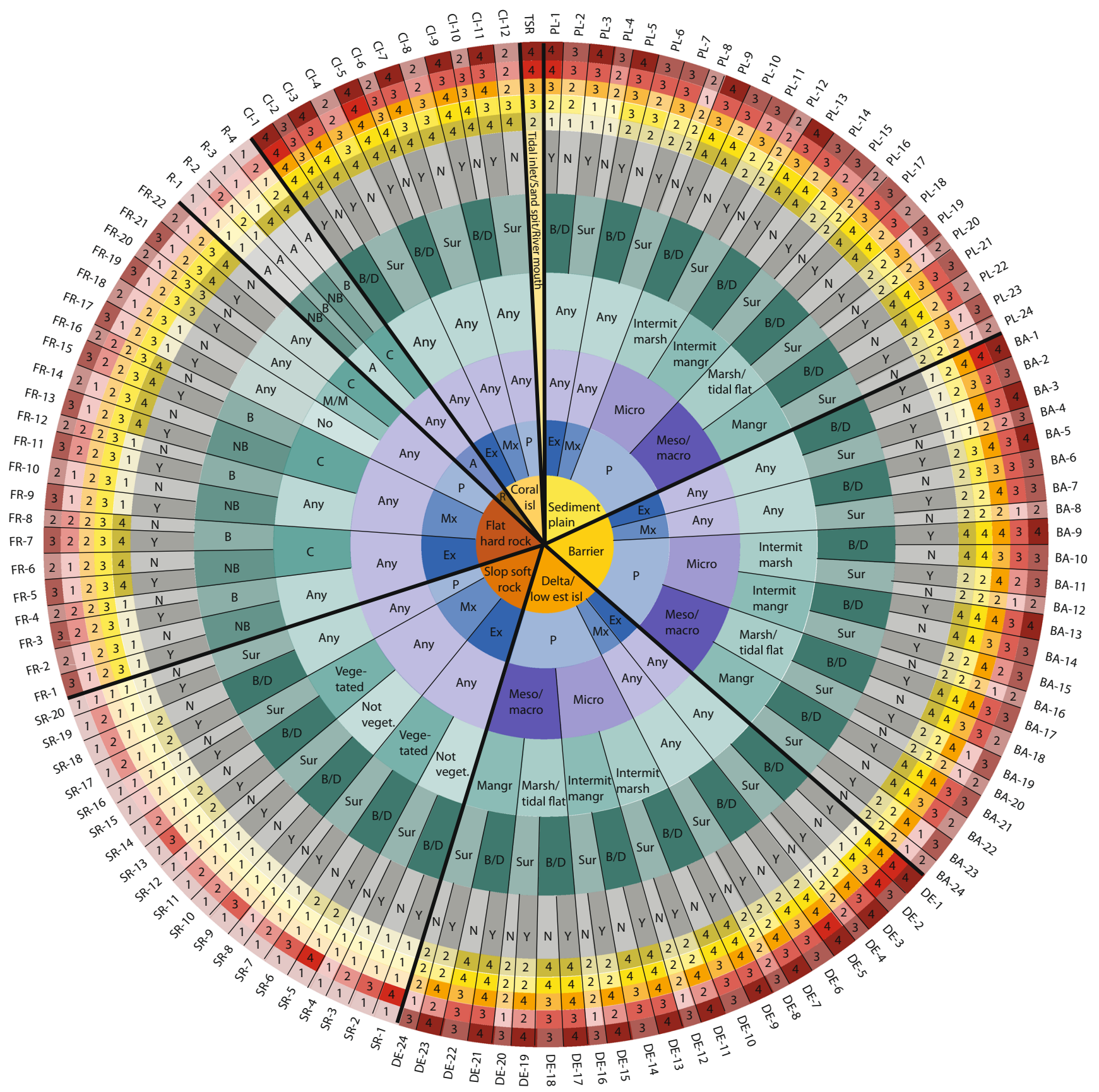

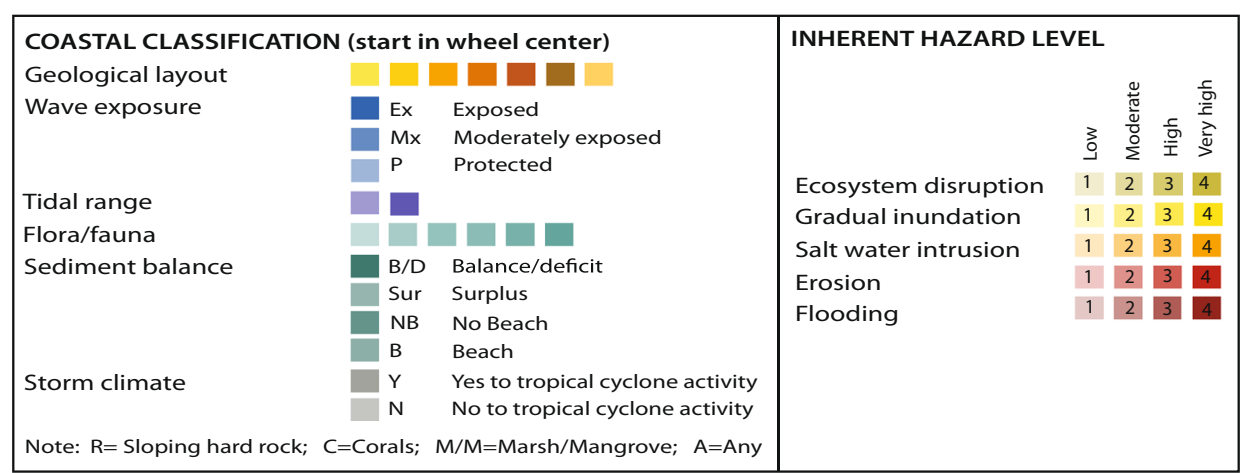

Fig. 3 The Coastal Hazard Wheel 2.0 (modified from Rosendahl Appelquist 2012) 
This step can generally be implemented based on remote sensing and publicly available data and is useful for hazard screening and for getting an initial picture of the hazard presence in a cost-efficient manner.

- Step 2 that is designed for hazard assessments with moderate accuracy and this step generally requires additional field verification of the data obtained though remotely sensing and public data sources.

- Step 3 that is designed for hazard assessments with high and locally focused accuracy and this step requires systematic and detailed field assessments at local level.

Generally, Step 1 and 2 are recommended for larger subregional, regional and national assessments, as it would require significant time and resources to implement Step 3 at this scale. Step 1-2 can therefore be used for broader hazard assessments, while Step 3 can be used for coastal stretches of specific interest or for detailed assessment of hazard-hotspots indentified at Step 1-2. Spot-assessments of a single coastal site can be carried out at any step depending on accuracy requirements, but it is important to be aware of the associated uncertainties if the assessment is carried out at Step 1-2. The following sections outline the data requirements and procedures for applying the CHW for multi-hazard-assessments.

Preparatory data collection and analysis

Prior to the actual assessment, it is necessary to collect and prepare appropriate input data for the different CHW classification components. Generally, the core data requirements remain the same for Step 1-3, but additional data is required for implementation of Step 2-3. The data requirements and preparatory analysis needed for each classification component are outlined in the following.

\section{Data for geological layout}

The core data requirements for classifying the geological layout at Step 1-3 are a general geologic map of the assessment area, Google Earth's satellite images and Google Earth's ground elevation function. The classification of the geological layout is done by combing information from these three data sources, and the geological map is used to assess whether the coastline is composed of soft or hard rock material, Google Earth's satellite images are used to get an overview of the coastal outline and indentify formfeatures as barriers, deltas, tidal inlets, sand spits, river mouths and islands, and Google Earth's ground elevation function is used to assess whether the coastline has a flat or sloping character.

To facilitate the assessment of the coastal slope, it is recommended to draw a supporting, shore-parallel, line-feature in Google Earth, landwards of the coastline in all areas with a slope greater than 3-4\% $200 \mathrm{~m}$ inland of the MSL. These coastal stretches can be identified by moving the curser in Google Earth from the approximate MSL and 200 inland (the distance can be estimated using Google Earth's ruler function) and monitoring the elevation in the button of the Google Earth window. If the elevation over this distance is more than 6-8 $\mathrm{m}$, the coastline is classified as sloping, and this procedure is repeated for every 100-300 m coastline. The supporting line-feature is then drawn landwards of the coastline in all areas categorized as sloping, using Google Earth's New Path function. Sloping coastal sections can then easily be indentified using the line-feature when the actual CHW assessment is carried out.

For implementing assessment Step 2, this data should be supplemented by representative field verification e.g. in areas where there are doubts about the geological base material, coastal outline or slope. An implementation of Step 3 would require systematic field verification at local level of all these parameters. In situations where no geological map is available for the assessment area, systematic data collection in the field can be used as a viable alternative. However, such an assessment will only be considered as a Step 1-2 assessment due to the lack of geological background information.

\section{Data for wave exposure}

The data requirements for classifying the wave exposure is the same for all Steps 1-3, namely Fig. 1 shown earlier, Google Earth's satellite images, Google Earth's ruler function and additional information on the general wind climate of the assessment area. The map shown in Fig. 1 is used to determine whether the coastal stretch in question can be considered as having a swell or non-swell wave climate, as defined in section "Wave exposure". All coastlines with a swell wave climate fall into the moderately exposed category, while the wave exposure of non-swell coastlines is determined through the free fetch. The free fetch is determined using Google Earth's satellite images and ruler function, assessing whether the free fetch is $<10 \mathrm{~km} ; 10-100 \mathrm{~km} ;>100 \mathrm{~km}$, defining protected, moderately exposed and exposed coastlines as mentioned in section "Wave exposure". Generally, it is recommended to supplement this information with literature on the local/regional/national wind climate to verify that the wind is actually blowing from the direction that is used as the free fetch length.

The nomogram mentioned in section "Wave exposure" may be used if very accurate exposure levels are considered relevant e.g. in relation to a Step 3 assessment. However, the free fetch evaluation, combined with basic information on the wind climate is regarded as the appropriate approach at all steps. The same exposure level may in some cases apply to long coastal stretches, but can also apply to very short sections in locations with a diverse coastal configuration. When the 
wave exposure is evaluated, it is also important to take human modifications of the coastline into account, since structures as harbours or breakwaters can change the wave exposure. If such structures are present, they should only be considered in the wave exposure evaluation if they can be regarded as permanent modifications of the coastal environment.

\section{Data for tidal range}

The data requirements for classifying the tidal range are the same for all Steps 1-3, namely Fig. 2 and, in some cases, supplementary tidal data for the assessment area. The map shown in Fig. 2 is used to identify whether the tidal range is of micro or meso/macro types, and in cases where the assessment area is close to any of the border areas, it is recommended to supplement the map with more detailed data on local tide conditions. Generally, such data is available on the internet, either as tidal tables from commercial harbours or in the scientific/technical literature. The same tidal range category often applies to long coastal stretches and once the tidal conditions are determined, it is relatively simple to go through this classification layer when the CHW assessment is carried out.

\section{Data for floralfauna}

The core data requirements for classifying the flora/fauna at Step 1-3 are Google Earth's satellite images, information on the latitude of the assessment area, information on the local marsh/mangrove flora and the UNEP-WCMC global coral reef database (Reefbase 2013). The Google Earth satellite images are used to visually evaluate the extension and type of coastal vegetation, the information on latitude and the information on the local marsh/mangrove flora is used to determine whether coastal wetlands are vegetated with marsh or mangroves, and the coral reef database is used to identify stretches of coastal coral reefs. As the flora/fauna classification is strongly dependent on the previous classification parameters, it makes this classification layer a bit more complex. It is therefore important to be aware of this close relationship when the CHW assessment is carried out. It may be difficult to determine the percentage of vegetation cover for sloping soft rock coastlines based on Google Earth's satellite images, and to avoid underestimating the hazard levels at Step 1, it is recommended to assume that the coastline has no vegetation in cases where there are doubts about the actual percentage.

For an implementation at Step 2, the data above should be supplemented by representative field verification of vegetation cover, vegetation type and if possible coral presence. Step 3 would require systematic field verification at local level for all these parameters.

\section{Data for sediment balance}

The core data requirements for classifying the sediment balance at Step 1-3 are Google Earth's satellite images and Google Earth's timeline function. The sediment balance is evaluated in two different ways depending on whether the geological layout falls into the sedimentary/soft rock or hard rock classification categories.

For all sedimentary/soft rock coastlines, it is determined whether the coastline in question has a sediment balance/ deficit or a sediment surplus. This is done using Google Earth's timeline function, which allows for an evaluation of the temporal changes in coastal development.

To facilitate the sediment balance evaluation in these areas, it is recommended to draw a supporting, shore-parallel, linefeature in Google Earth, at the approximate vegetation line at all sedimentary/soft rock stretches of the assessment area. The line-feature should be based on the most recent satellite image layer in Google Earth. When the actual CHW assessment is carried out, it is then relatively simple to determine whether the coastline has been stable (sediment balance), retreating (sediment deficit) or prograding (sediment surplus) by shifting back and forth between different satellite images, and comparing the older images with the digitized, most recent coastal vegetation line. In some locations, especially at desert coastlines, the vegetation line might not be present and therefore not possible to use as reference line. Also, it may be difficult to determine a clear vegetation line at protected coastlines with a high tidal range. Under these circumstances, the user can either try to draw the supporting line-feature at the approximate vegetation line or at the approximate MSL, but the uncertainties related to this should be kept in mind. An assessment based on the approximate MSL is generally not optimal as the satellite images in Google Earth are captured at different tide conditions and at different times of the year and can therefore be captured at very different water levels. Hence, the visible water level cannot be directly compared between the different images. Also, it is important to be aware of possible human alterations of the sediment balance such as beach nourishment, sand mining or upstream river damming. A human modification of the coastal environment should only influence the sediment balance classification if it is of permanent character, and if there are any doubts it is recommend to apply the sediment balance/deficit classification to avoid underestimating the hazard levels.

For all hard rock coastlines, the sediment balance is classified by determining if some kind of beach environment is present based on Google Earth's satellite images.

For an implementation at Step 2, the data for sedimentary/ soft rock coastlines should be supplemented by representative field verification of signs of longer term erosion/accretion and human alterations. For hard rock coastlines, representative field verification should be carried out to assess the presence 
of beach environments. Step 3 would require systematic field verification at local level for all these parameters.

\section{Data for storm climate}

The data requirement for identifying if tropical cyclones are present in the assessment area is the same for all Steps 1-3 and is simply Fig. 1 shown in section "Wave exposure".

\section{Assessment procedure}

The actual assessment procedure can be carried out when the preparatory data collection and analysis mentioned in section "Preparatory data collection and analysis" has been completed. The assessment is carried out using the CHW and is done through a range of continuous assessments along the coastline, with an approximate distance between each assessment of 100-300 m. For spot-assessments it may be appropriate simply to note the results of the hazard assessment for the coastal site in question. For local, regional and national assessments, however, it is recommended to conduct the analysis in ArcGIS, as this allows for a more systematic assessment procedure and subsequent development of high-quality hazard maps for ArcGIS and if relevant hazard layers for Google Earth.

When the assessment is carried out in ArcGIS, the first step is to create an ArcGIS geodatabase that will contain all data on the coastal classification and subsequent hazard levels. In order to have a relatively detailed and up-to-date coastline of the assessment area that can be used for the assessment, a new line-feature is created in the geodatabase referencing the relevant UTM Zone for the assessment area. The full coastline of the assessment area is then digitized at the approximate MSL using this line-feature, leaving gaps for river mouths and tidal inlets. The accuracy of this digitization should be approximately $10 \mathrm{~m}$, as the digitized coastline will function as basis for all subsequent coastal hazard maps.

The coastal classification is carried out on top of the digitized coastline in ArcGIS. This is done using a polygon feature created in the geodatabase, using the same UTM zone as the digitized coastline. The polygon feature is used to split the coastline into smaller sections, each being classified according to the CHW classification system. The sections are stored in a so called linear referencing system that keeps track of the sections based on a simple measuring system defined along the coastline (Balstrøm 2008). The practical assessment is done manually by drawing a new polygon every time the coastline changes to a new coastal type according to the CHW classification system, and during this process, it is important to establish a snapping environment in ArcGIS to make sure that the polygons are properly aligned with each other.
Since the classification is carried out manually based on the $\mathrm{CHW}$ and the data mentioned in section "Preparatory data collection and analysis", the user has to decide on an appropriate coastal type when drawing each polygon. Sometimes a coastline can maintain the same properties for many kilometers, while at others, it changes every $100 \mathrm{~m}$. This means that the length of each polygon can vary significantly for the different parts of the coastline of the assessment area.

The optimal way of adding the CHW classification code to each polygon is to create an attribute domain that can contain the codes of all coastal types included in the $\mathrm{CHW}$, along with the associated hazard values. The attribute table used for the polygons then includes the predefined $\mathrm{CHW}$ classification codes that can be selected when each polygon is drawn. Subsequently, the hazard values in the table can be used for developing the hazard maps.

When the polygons have been drawn for the full length of the coastline in question, they are used to divide the initial digitized coastline into sections, each representing a specific coastal type. This is done using the locate features along routes function in ArcGIS. Based on this, five different hazard maps are created for the respective hazards types and the different hazard levels are assigned a colour code. The hazard maps can e.g. be created on top of a hybrid Bing map to optimize the visual readability. In addition to this, separate hazard layers can be developed for use in Google Earth to allow users getting a more detailed picture of the hazard presence (Rosendahl Appelquist and Balstrøm 2014, 2015).

\section{Application examples}

The CHW has been applied for multi-hazard-assessments in selected locations using the methodology described above. Figure 4 shows an example from the application of the CHW 1.0 for a multi-hazard-assessment of the state of Karnataka, India, at Step 1. The example shows two subregional hazard maps for northern Karnataka, displaying the hazards of erosion and flooding (Rosendahl Appelquist and Balstrøm 2015).

Figure 5 shows an example from the application of the preliminary version of the CHW 2.0 on the state of Djibouti. The figure shows the hazard of ecosystem disruption for the full length of Djibouti's coastline, and as part of this project, similar maps were developed for gradual inundation, salt water intrusion, erosion and flooding, along with hazard layers for use in Google Earth.

Generally, a standard multi-hazard-assessment would result in a series of hazard maps, coving the five hazard types included in the CHW system. The hazard maps shown in Figs. 4 and 5 are therefore mainly for illustration, and the full range of hazard maps developed for Karnataka and Djibouti can found in the related papers (Rosendahl Appelquist and Balstrøm 2014, 2015). 
Fig. 4 Sub-regional hazard maps for northern Karnataka, India showing the hazards of erosion and flooding (Rosendahl Appelquist and Balstrøm 2015)

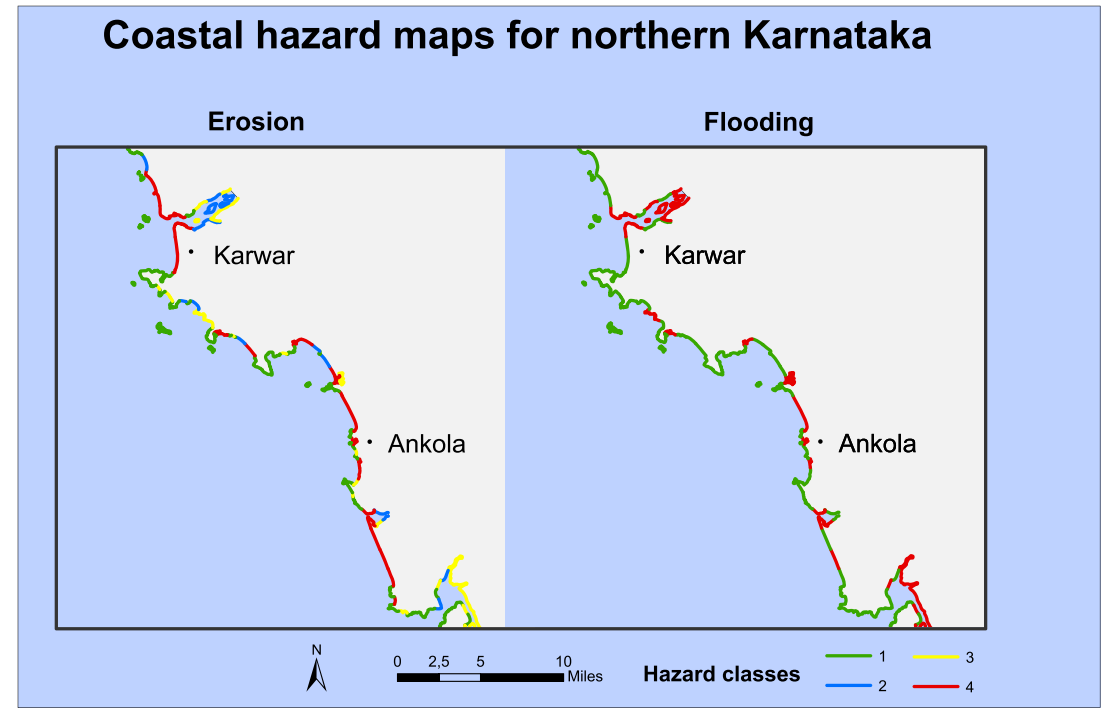

\section{Identification of hazard management options}

Together with hazard assessments, the CHW system can be used for identifying relevant hazard management options for the different coastal environments. Figure 6 shows a matrix of how the most commonly used management options apply to the different coastal environments in the CHW, and which hazard types they primarily address. The included management options can be used for mitigating one or more hazard types and can be used in isolation or as combined measures. It

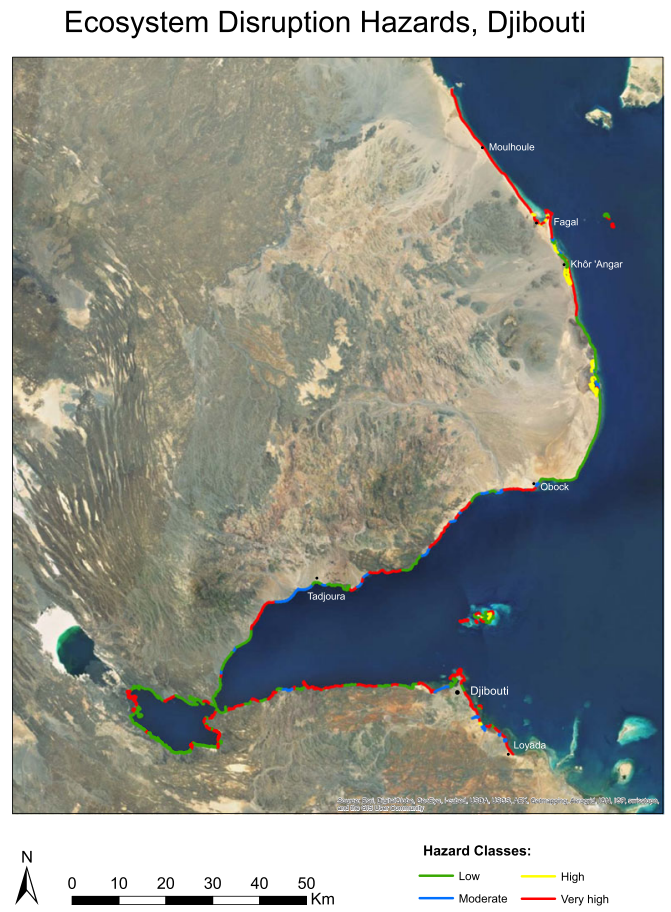

Fig. 5 National hazard map for Djibouti showing the hazard of ecosystem disruption (Rosendahl Appelquist and Balstrøm 2014) should be noted, however, that the choice of management option depends on a range of different factors beyond the technical effects of the management option, including project costs, durability, simplicity, flexibility over time, availability of material, labour and equipment and the related socioeconomic and geographical context.

In the matrix, the geological layout categories Sedimentary plain, Barrier and Delta/low estuary island are considered together for simplification purposes, as the management options available for these layouts are relatively similar. The categorization of the different management options are assigned by the authors, based on the current literature of their normal application.

The matrix covers the three main types of management options, namely hard protection measures, soft protection measures and accommodation approaches, that all can be relevant under different circumstances and have different strengths and weaknesses.

\section{Hard protection measures}

The hard protection measures are listed first in Fig. 6 and include breakwaters, groynes, jetties, revetments, sea walls, dikes and storm surge barriers. They are considered the traditional approach to coastal defence and make use of hard structures to create a solid barrier between the land and sea that can resist wave and tide energy, thereby preventing land/sea interaction (Linham and Nicholls 2010). The fixation of the coastline can be beneficial for protecting specific areas of interest but creates a lot of other problems as it prevents the natural coastal dynamics from taking place. The key characteristics and applications of the different hard protection measures are outlined below. 


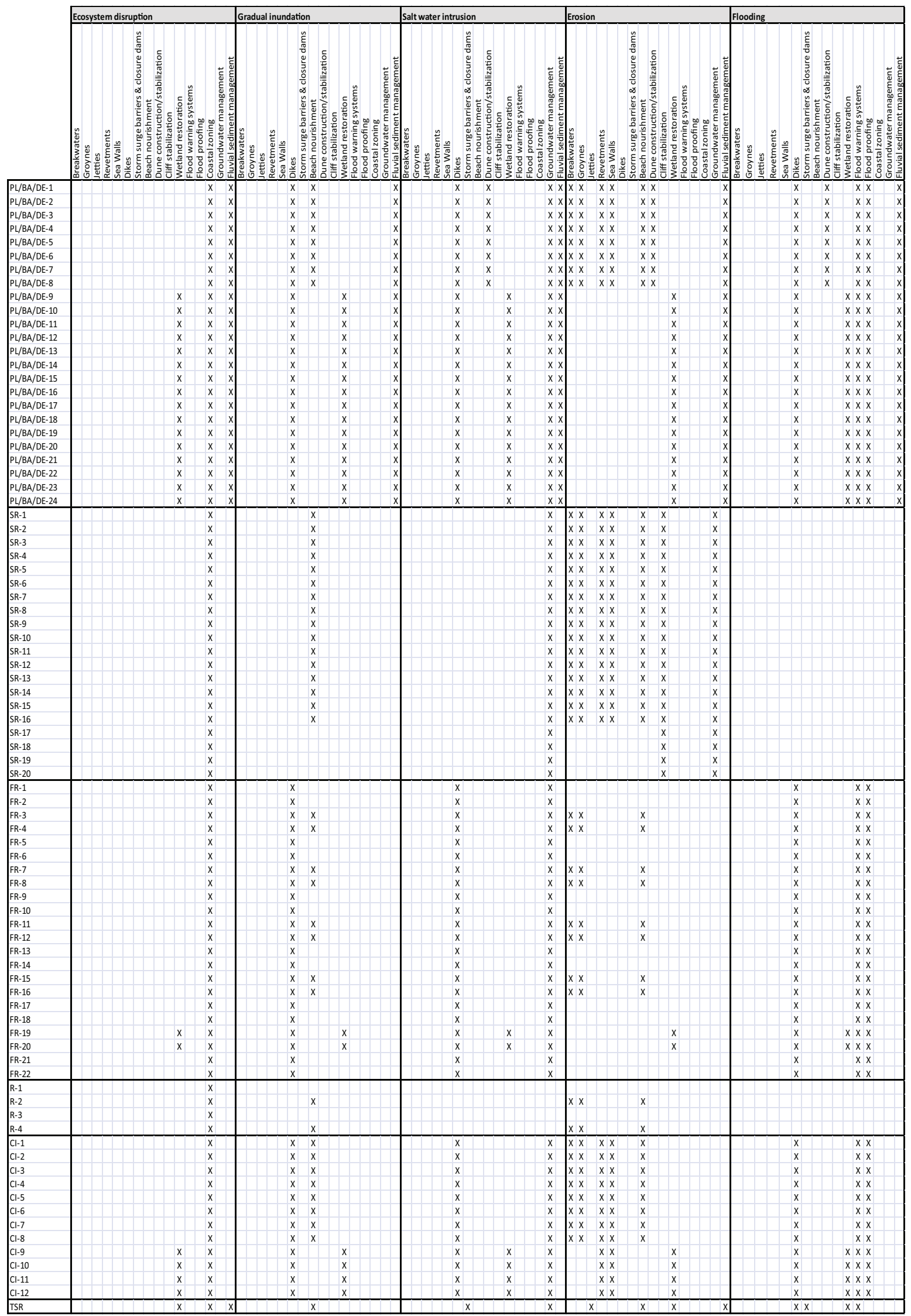

Fig. 6 Matrix of hazard management options for the different coastal environments of the CHW 
Breakwaters, sometimes termed detached breakwaters, are shore-parallel structures situated just offshore the surf zone to intercept with incoming waves, thereby reducing incoming wave energy. They are normally built in exposed and moderately exposed sedimentary coastlines, mainly to address erosion hazards but can also have some secondary effects on flooding hazards as they protect dune fields, sea walls and dikes from wave attack. They are usually build in a series to protect longer coastal stretches and are constructed from rock armour, poured concrete, dolos or tetrapods (Davis and Fitzgerald 2004). Key design parameters include the gap between the breakwaters, their length, their off-shore distance and the size of the rock armour used (Masselink and Hughes 2003; Paulsen 2012/2013). Breakwaters provide a sheltered beach area behind them and the wave refraction/diffraction patterns lead to sediment deposition in the lee-side of the structure, sometimes resulting in salient or tombolo formation. Generally, breakwaters form a good alternative to groynes and are able to support beach formation without blocking the littoral drift if they are designed to avoid tombolo formation. However, the structures have to be very large and robust to withstand the high wave exposure of deeper water and can suffer damage during storm events (Masselink and Hughes 2003; Davis and Fitzgerald 2004). Problems with breakwaters are related to interference with longshore sediment transport and erosion drowndrift of the breakwaters. Also, deep holes can develop between breakwaters, which present a hazard for recreational use of the coast (Davis and Fitzgerald 2004).

Groynes are hard structures constructed perpendicular to the beach to trap a portion of the longshore sediment transport and thereby build and stabilize beach environments. They are normally built in exposed and moderately exposed sedimentary coastlines to address erosion hazards. They can be constructed from rock armour, concrete, dolos, tetrapods and timber and are often constructed as a series in a groyne field. The dimensions between groyne length and groyne spacing generally varies from $1: 4$ on sandy beaches to $1: 2$ on gravel beaches, and conventional practice is that groyne length should be approximate $40-60 \%$ of the average surf zone width. This allows the groynes to trap some, but not all, of the littoral drift (Masselink and Hughes 2003). Drawbacks of groynes include the possibility of sediment starvation and erosion further downstream, especially if the structures are not designed properly and trap too much sediment. Another problem is related to formation of rip currents adjacent to groynes that can present a hazard to swimmers and lead to sediment being transported to deep water and lost from the coastal system during storm events (Masselink and Hughes 2003). The ideally designed groyne field allows sediment to accumulate and eventually bypass the buried groyne, without causing significant downdrift erosion. However, the ideal design is rarely achieved due to lack of detailed data on wave climate and long-shore sediment transport rates (Davis and Fitzgerald 2004).
Jetties are much like groynes in all respects, except that they are typically larger (Davis and Fitzgerald 2004). They are built to line the banks of tidal inlets or river mouths in order to stabilize one or both sides from shifting position and to preventing large volumes of sand from filling the inlet. Also, they can be used to prevent spit growth into a tidal inlet. Like groynes, they cause an interruption of the long-shore sediment transport and lead to sediment accumulation on their updrift side and sediment starvation on their down-drift side (Masselink and Hughes 2003). Since jetties can be very long, tremendous amounts of sediment can be trapped this way, leading to major setbacks of the coastline on the down-drift side (Davis and Fitzgerald 2004). Impacts on long-shore sediment transport are therefore a critical design parameter.

Revetments are shore-parallel, sloping structures, constructed landwards of the beach to protect a dune area, coastal slope, dike or sea wall from wave exposure. They are mainly built on exposed and moderately exposed sedimentary coastlines to address erosion hazards, but can also have secondary effects on flooding and gradual inundation hazards depending on what they are designed to protect. They are built from rock armour, dolos or tetrapods and are designed to maximize dissipation of wave energy due to their gentle slope and loose material (Masselink and Hughes 2003). Because they are static structure they conflict with the natural coastal dynamics and may cause accelerated erosion of adjacent unprotected coastlines due to their effect on the long-shore sediment transport and dynamic processes.

Sea walls are shore-parallel, vertical or sloping structures generally constructed in backbeach environments. They are built mainly on exposed and moderately exposed coastlines to address hazards of erosion and sometimes indirectly flooding, and are constructed from rock blocks, bulkheads of wood or steel and concrete. If the sea wall is vertical, it is highly reflective and can cause scouring of the beach in front of the wall and subsequently beach loss and collapse of the wall. More concave sea walls are still reflective but introduce a dissipative element, reducing risk of beach loss and undermining (Masselink and Hughes 2003). Other problems with sea walls are related to reflection of wave energy that can cause problems elsewhere, erosion of shorelines adjacent to the sea wall due to disruption of long-shore sediment transport and a generally unsightly appearance (Davis and Fitzgerald 2004). Vertical and impermeable sea walls generally cause the greatest problems while concave structures or sea walls combined with rock revetments that allow some dissipation of wave energy have less negative effects (Davis and Fitzgerald 2004). Sea walls are generally expensive and only temporary and often create a long range of new problems. However, they may be an appropriate solution to protect expensive property and infrastructure. To maintain the recreational properties of the coast and address the problems of beach loss and undermining, sea walls may be combined with a beach nourishment scheme (Davis and Fitzgerald 2004). 
Dikes are shore-parallel features constructed in all types of low-lying coastlines. They are built for flood defence rather than erosion protection and are normally constructed between mean spring tide level and the highest astronomical tide (Masselink and Hughes 2003). They are usually build of unconsolidated material as clay and may be combined with harder erosion protection measures such as revetments if they are constructed in environments with wave exposure. The main problem with dikes is related to the process of coastal squeeze, where natural coastlines seaward of the dike gets increasingly reduced in size with rising sea level (Masselink and Hughes 2003).

Storm surge barriers and closure dams are hard structures with primary purpose of preventing coastal flooding. They are constructed in tidal inlets, river mouths and harbour areas and can be easily integrated with larger flood protection systems. Storm surge barriers are movable or fixed barriers or gates which are closed at high water levels and are generally large scale coastal defence projects (Linham and Nicholls 2010). Closure dams are a more low-tech option and consist of non-movable barriers. However, both systems generally have high construction and maintenance costs.

\section{Soft protection measures}

The soft protection measures shown in Fig. 6 have largely been developed as a response to the negative effects of hard defences and represent a major shift in approach from an adhoc management of coastal hazards to a more holistic and proactive approach (Linham and Nicholls 2010). Soft engineering allows the natural coastal dynamics to exist and maintains the natural landscape and habitat function. The main types of soft protection measures include beach nourishment, dune construction/rehabilitation and cliff stabilization, and their application is outlined in the following.

Beach nourishment is the artificial deposition of sediment on the beach or in the nearshore zone to stabilize or advance the shoreline seaward. It is mainly used on exposed and moderately exposed sedimentary coastlines for erosion control, but some benefits in relation to flooding and gradual inundation may also occur (Linham and Nicholls 2010). Beach nourishment functions by compensating for a sediment deficit, either from loss of sediment or a rising sea level, while at the same time maintaining the natural coastal dynamics. As sediment often continues to be lost from the beach, beach nourishment has to be carried out with regular intervals. It may also be considered relevant to combine beach nourishment with groyne construction to limit sediment loss, although this interferes with the natural coastal dynamics. As a general rule, the size of the sand used for beach nourishment should be equal or coarser than the local sediment, to minimize rapid loss of sediment offshore (Masselink and Hughes 2003).
Furthermore, it is important to take the local bathymetry and wave conditions into account in the design process, and sediment borrowing areas should be selected to cause minimal damage to the marine ecosystems. The sand used for beach nourishment should be essentially free of mud in order to avoid problems with turbidity and ecosystem damage (Davis and Fitzgerald 2004). Problems with beach nourishment are often related to public perception, as the natural redistribution of sediment from the visible beach to the nearshore zone can give the impression of failure of the nourishment. However, the sediment is not lost from the system but stays in the nearshore zone, providing wave protection and a sand reservoir. Beach nourishment is increasingly becoming the preferred option for coastal protection as it is relatively cost-efficient and maintains the natural coastal environment. Also, it can be used to complement hard protection measures such as sea walls, which can then be used as a last line of defence (Linham and Nicholls 2010).

Dune construction/stabilization aims at controlling coastal erosion and flooding of adjacent lowlands and is used on exposed and moderately exposed flat, sandy coastlines. Dunes are generally fragile of nature and are easily disrupted by a footpath or a wind blowout, but can provide good coastal protection. Dune construction is normally achieved by use of fences that are placed at selected places on the backbeach. They thereby disrupt the airflow and promote sediment deposition on both sides of the fence and a well-designed fence system in an area with abundant aeolian sediment transport can lead to vertical dune growth of more than $1 \mathrm{~m} /$ year (Masselink and Hughes 2003). Planting of vegetation can also be used instead of fences or for stabilizing existing dunes. Problems with dune stabilization through fences is that they prevent dune migration during washover and the result may be accelerated erosion and sediment removal on the seaward side of the dune by wave attack (Davis and Fitzgerald 2004). Construction of walkovers can prevent destruction of dune vegetation when the coast is used for recreation. Dune construction/stabilization can also be carried out in association with beach nourishment, using dredged sediment (Linham and Nicholls 2010).

Cliff stabilization aims at reducing cliff erosion at sloping soft rock coasts due to precipitation, groundwater seeping and wave attack. Cliff stabilization is carried out through planting of vegetation, terracing and drainage of excess precipitation and groundwater. In exposed and moderately exposed coastlines, this can be combined with some kind of hard or soft wave protection measures to minimize erosion of the clifffoot.

\section{Accommodation approaches}

The accommodation approaches listed in Fig. 6 involve the continued occupancy and use of vulnerable coastal areas by 
increasing society's ability to cope with the effects of coastal dynamics and extreme events. These approaches should be implemented proactively and requires advanced planning and acceptance of the coastal zone as a dynamic area that undergoes continuous change (Linham and Nicholls 2010). Some of the main types of accommodation approaches include wetland restoration, flood warning systems, flood proofing and coastal zoning, that are outlined in the following.

Wetland restoration aims at reducing the hazards of ecosystem disruption, gradual inundation, erosion and flooding, along with restoring habitats and coastal ecosystems. Most commonly wetland restoration applies to protected, lowlying coastlines with marsh and mangrove ecosystems. These natural systems provide important environments for dissipation of wave and tidal energy and trapping of sediment, helping to stabilize the coastline (Linham and Nicholls 2010). Wetland restoration can take place in various forms and include transplantation of seedlings from other sources such as nurseries and elevation of selected areas using additional material. Generally, wetland restoration makes use of the natural protective mechanisms of coastal wetlands and thereby combines coastal protection with a conservation of the natural coastal ecosystems.

Flood warning systems aim at providing an early detection and preparation of flood events and can be relevant in all lowlying coastal environments. These systems allow the public and relevant institutions to take appropriate measures in due course, thereby reducing the general exposure of people and property to coastal flooding (Linham and Nicholls 2010). Flood warning systems can be implemented together with a range of other adaptation measures and are a necessity for the use of storm surge barriers.

Flood-proofing is used to reduce the impacts of coastal flooding on physical structure in low-lying areas and generally, one distinguishes between wet and dry approaches. Wet approaches work by allowing flood water to easily enter and exit a structure in order to minimize structural damage, by using materials that can tolerate flooding and by elevating relevant components. Dry approaches work by making structures watertight or relatively impermeable to the expected flooding height (Linham and Nicholls 2010). The advantages of flood-proofing are that it avoids the need of relocation and elevation of structures. However, it may have to be combined with evacuation schemes to limit the exposure of people to extreme events.

Coastal zoning is a relatively easy and efficient way of managing different uses of the coastal zone and depending on the local conditions, it can be relevant for coastal development, coastal wetland management and protection of fragile marine habitats. Activities in a particular zone can be allowed, allowed with permission or forbidden and can be used in relation to economic development, tourism and conservation. In
Australia, the Great Barrier Reef Marine Park uses this approach (Haslett 2009).

In addition to the hazard management options listed above, there exists a range of other coast- related management measures such as groundwater management, management of fluvial sediment supply to the coastline and delta areas (both included in Fig. 6), ecosystem based management of coastal and marine ecosystems and complete human retreat from the coastline.

\section{Cost examples of hazard management options}

The cost of the different hazard management options is one of the essential, non-technical parameters when deciding upon appropriate management strategies. This section therefore provides a short overview of cost examples based on data collected from coastal management projects over the last two decades and recent data from international dredging companies. The cost examples are intended to provide an indication of the cost levels and cost components for the different hazard management options and can contribute to discussions of appropriate hazard management strategies for the different coastal environments.

The cost of some hazard management options, such as dike construction and wetland restoration, can vary significantly as they largely depend on local labour and material costs. Other management options, such as rock armour structures and beach nourishment have more comparable global cost levels, as they in many cases are implemented by international dredging companies using comparable materials and equipment. The following sections try to the give an indication of the cost levels for most of the management options covered in section "Identification of hazard management options", distinguishing between hard protection measures, soft protection measures and accommodation approaches.

\section{Cost examples of hard protection measures}

The cost of hard protection measures depends on local project conditions, the type of structure put in place and the material used. The cost of hard measures generally consists of a large construction cost, followed by some varying O\&M costs. Figure 7 provides an overview of the construction costs of a range of different hard protection projects that are designed or implemented over the last ca. 20 years. The costs are provided in $€ /$ meter structure and have been converted to Euros using the currency conversion rates for the year the project was designed/implemented. The project examples include exposed rock breakwaters, moderately exposed rock breakwaters, exposed steel/wood/rock groynes, exposed rock/concrete revetments, moderately exposed rock revetments, exposed sea walls and moderately exposed sea walls. The examples are 
Fig. 7 Construction costs for hard protection projects over the last ca. 20 years in $€ /$ meter structure. The projects types listed from left are: Exposed rock breakwaters, moderately exposed rock breakwaters, exposed groynes, exposed revetments, moderately exposed revetments, exposed sea walls and moderately exposed sea walls (Cipriani 2004; Cipriani and Pranzini 2012; COWI 2009a; El Raey et al. 1999; Environment Agency 2012, 2010; Evans 2012; Farrow 2012; Hillen et al. 2010; Pelliccia 2004; Povilanskas 2004b;

Rosbæk 2012; Schoeman 2004; Sistermans 2004; Skaarup 2004; Slagelse Kommune 2009; Spyropoulos 2004; Thisted Kommune 2008)

\section{Construction costs of hard protection measures ( $€ /$ meter structure)}

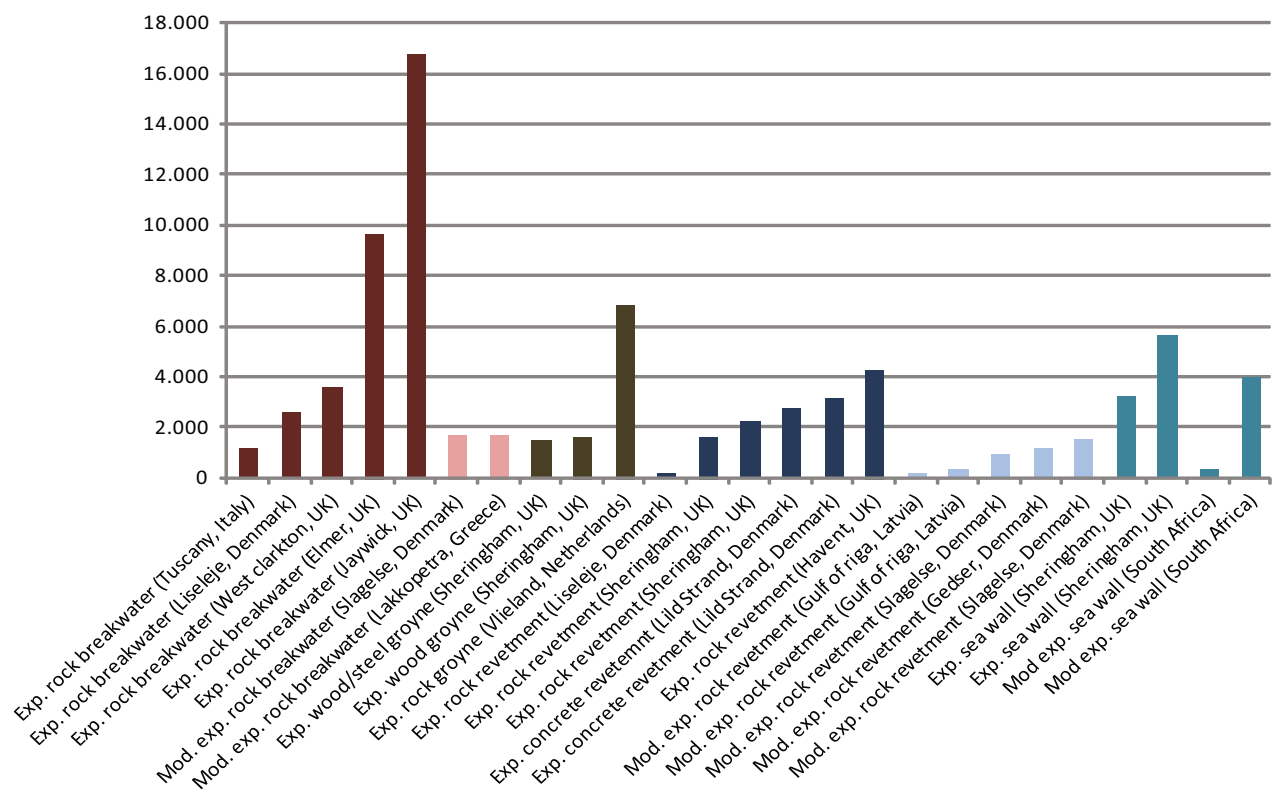

sorted according to the type of structure and construction costs, and the wave exposure levels for the different projects have been estimated based on the wave climate and free fetch length of the construction site. It has not been possible to obtain the approximate O\&M costs for the listed projects. Since the cost numbers have been calculated based on a range of different data sources, including research papers, project documents, company reports and personal communication with project managers, they are associated with different levels of uncertainty. Furthermore, cost variations over time affect the cost numbers. From the figure it can be seen that the construction costs of especially exposed rock breakwaters vary significantly, while the remaining measures to some degree stay within the same cost range. The high cost of some of the exposed breakwaters may be explained by the need for very robust structures in some locations to avoid damage from wave attack.

The overall project costs depend on a range of different cost components that varies depending on project type and local conditions. To allow for a more detailed cost estimation for hard protection projects using rock armour, data has been collected for the different cost components. Table 1 provides an example of the magnitude of the different cost components in 2012 for rock armour structures constructed by the dredging company Boskalis. The costs are broken down into cost of rock quarrying and delivery on large pontoon at the shipment site, long distance transport by pontoon, short distance transport by pontoons at the project site and placement by grabdredger. The numbers shown are realistic examples of the magnitude of costs for standard projects and the costs are expected to increase by $10-50 \%$ for projects with higher business risks such as projects in developing countries (Paulsen 2012).

In order to provide data from two independent sources, Table 2 shows an example of the different cost components

Table 1 Realistic example of cost components for rock armour structures by Boskalis in 2012 prices (Paulsen 2012)

Cost of rock armour structures (Boskalis example)

Rock quarry \& delivery on large pontoon at shipment site

Large rocks bigger than 1 ton

30 Euro/ton

Mixed size rocks

20 Euro/ton

Long distance transport with large pontoon

Cost for pontoon

10.000 Euro/day

Capacity

10.000 ton

Approximate cost for long distance rock transport 1 Euro/ton/day

Pontoon speed

5 knots

Shuttle pontoons for short distances to placement site

Cost for pontoon loading

1 Euro/ton

Cost for pontoons (with two pontoon shift)

Cost for tugboat

2 Euro/ton

Placement ship — grab dredger

Operation cost

1 Euro/ton

Capacity

Approximate weekly capacity

100.000

Euro/week

100 ton/hour

Approximate cost for placement
10.000 ton

10 Euro/ton 
Table 2 Realistic example of cost components for rock armour structures by Van Oord in 2012 prices (Lindo 2012)

Cost of rock armour structures (Van Oord example)

$\begin{array}{ll}\text { Breakwaters/Groynes/revetments } & \\ \text { Purchase and transport of rocks based on } & 20 \text { Euro/ton } \\ \text { transport distance of } 50 \mathrm{~km} & \\ \text { Placing (combination of dry and waterborne placing) } & 30 \text { Euro/ton }\end{array}$

for hard protection measures by the dredging company Van Oord in 2012. The table is less detailed than Table 1 and shows the cost of purchase and transport of rocks, assuming a transport distance of $50 \mathrm{~km}$ and the cost of combined dry and waterborne placing. It should be mentioned that these costs are rough examples and can vary significantly depending on the quality of the rock/quarry, transport conditions, physical conditions at the project site and other business risks. It can be seen that the cost levels for the two data sources listed in Tables 1 and 2 are relatively similar although Table 2 does not provide the same level of detail.

For every specific hard protection project using rock armour, construction dimensions should be determined based on detailed engineering considerations on a case-by-case basis. Generally, breakwaters in both exposed and moderately exposed locations make use of larger rocks of the size of 1-3 t, but smaller rocks of $<1 \mathrm{t}$ can be used for the breakwater core. Breakwaters are constructed in the form of a trapeze and can vary significantly in size depending especially on wave exposure but it is possible to provide some rough magnitude examples. An exposed breakwater constructed at $4 \mathrm{~m}$ water depth could be $8 \mathrm{~m}$ high and have top and bottom widths of $7 \mathrm{~m}$ and $20 \mathrm{~m}$ respectively. The rock need could be approximately $2,1 \mathrm{t}$ rock $/ \mathrm{m}^{3}$ breakwater, if large rocks are used (Paulsen 2012). A breakwater constructed at a moderately exposed coastline at $2 \mathrm{~m}$ water depth could be $3 \mathrm{~m}$ high and have top and bottom widths of $3 \mathrm{~m}$ and $8 \mathrm{~m}$ respectively. The rock need could similar to an exposed breakwater be approximately 2,1 trock $/ \mathrm{m}^{3}$ breakwater (Paulsen 2012). Geotextile is often used below breakwaters, groynes and revetments and have an approximate cost of $20 € / \mathrm{m}^{2}$ (Paulsen 2012). The length and space between the breakwaters depends of the specific breakwater scheme and can vary significantly, and the same applies to maintenance needs. Groynes of rock armour can be constructed using both large and small rocks depending on the wave exposure and environmental conditions of the project site, and typical groyne lengths are described in section "Identification of hazard management options". Groynes of rock armour often have the form of a trapeze, but the specific groyne dimensions depend on the local coastal profile and physical conditions and hence dimension examples are not provided here. Revetments are usually constructed of smaller rocks of $<1$ ton, although lager rocks can be used under exposed conditions. In exposed locations, revetments can have a thickness in the order of $3 \mathrm{~m}$, while they tend to be $2 \mathrm{~m}$ thick at moderately exposed locations.

The costs of hard protection measures using concrete such as sea walls are strongly dependant on local labour and material costs as well as the properties of the structure. It is therefore difficult to provide general examples of the different cost components. For the UK, the Environment Agency has estimated the cost of a standard sea wall to about $€ 2,1$ million $/ \mathrm{km}$ and a reinforced concrete sea wall to about $€ 7$ million $/ \mathrm{km}$ (Environment Agency 2010). For sea walls in India, the cost in 2003 was estimated to be in the order of above $€ 30.000 / \mathrm{km}$ coastline (Jayappa et al. 2003).

The cost of dikes is also strongly dependent on local labour and material costs and the physical properties of the structure and it is therefore difficult to provide representative cost examples. Hillen et al. (2010) has compiled the cost of sea dikes in the Netherlands, New Orleans, USA and Vietnam and here the total engineering cost ranges from $€ 0,75$ million $/ \mathrm{km}$ to $€ 21,6 \mathrm{million} / \mathrm{km}$ for every $1 \mathrm{~m}$ of dike height in 2009 prices. More specifically, the cost in the Netherlands ranges from $€ 4$ to $€ 21,6$ million $/ \mathrm{km}$ for every $1 \mathrm{~m}$ of dike height, in New Orleans from $€ 5-€ 8$ million/ $\mathrm{km}$ for every $1 \mathrm{~m}$ of dike height and in Vietnam from $€ 0,75$ to $€ 1,2$ million $/ \mathrm{km}$ for every $1 \mathrm{~m}$ of dike height (Hillen et al. 2010). As can be seen, there is a major span in the cost numbers with dike costs in Vietnam being many times lower than in the Netherlands and USA, which is related to differences in material and labour costs and other local parameters. Estimates of maintenance costs for dikes varies significantly for different locations but are reported to range from $€ 0,03$ million/ $\mathrm{km} /$ year in Vietnam to $€ 0,15$ million/ $\mathrm{km} / \mathrm{year}$ in the Netherlands in 2009 prices (Hillen et al. 2010; Linham and Nicholls 2010).

\section{Cost examples of soft protection measures}

The cost of soft protection measures can vary significantly depending on approach and location but the cost of beach nourishment can to some degree be compared at global level. Parameters that affect the cost is sand availability, sand quality, project size, transportation costs, physical conditions at the dredging and nourishment locations and business risks such as fuel prices, technical and security risks. Beach nourishment is generally implemented as a continuous scheme with regular nourishments of a particular coastal stretch. Figure 8 provides an overview of the cost levels in $€ / \mathrm{m}^{3}$ sand for a range of beach nourishment projects carried out predominantly in Europe over the last ca. 20 years. The costs have been converted to Euros using the currency conversion rates for the year the project was designed/implemented. From the figure it can be seen that the cost for most beach nourishment 
Beach nourrishment costs

$(€ / \mathrm{m} 3)$

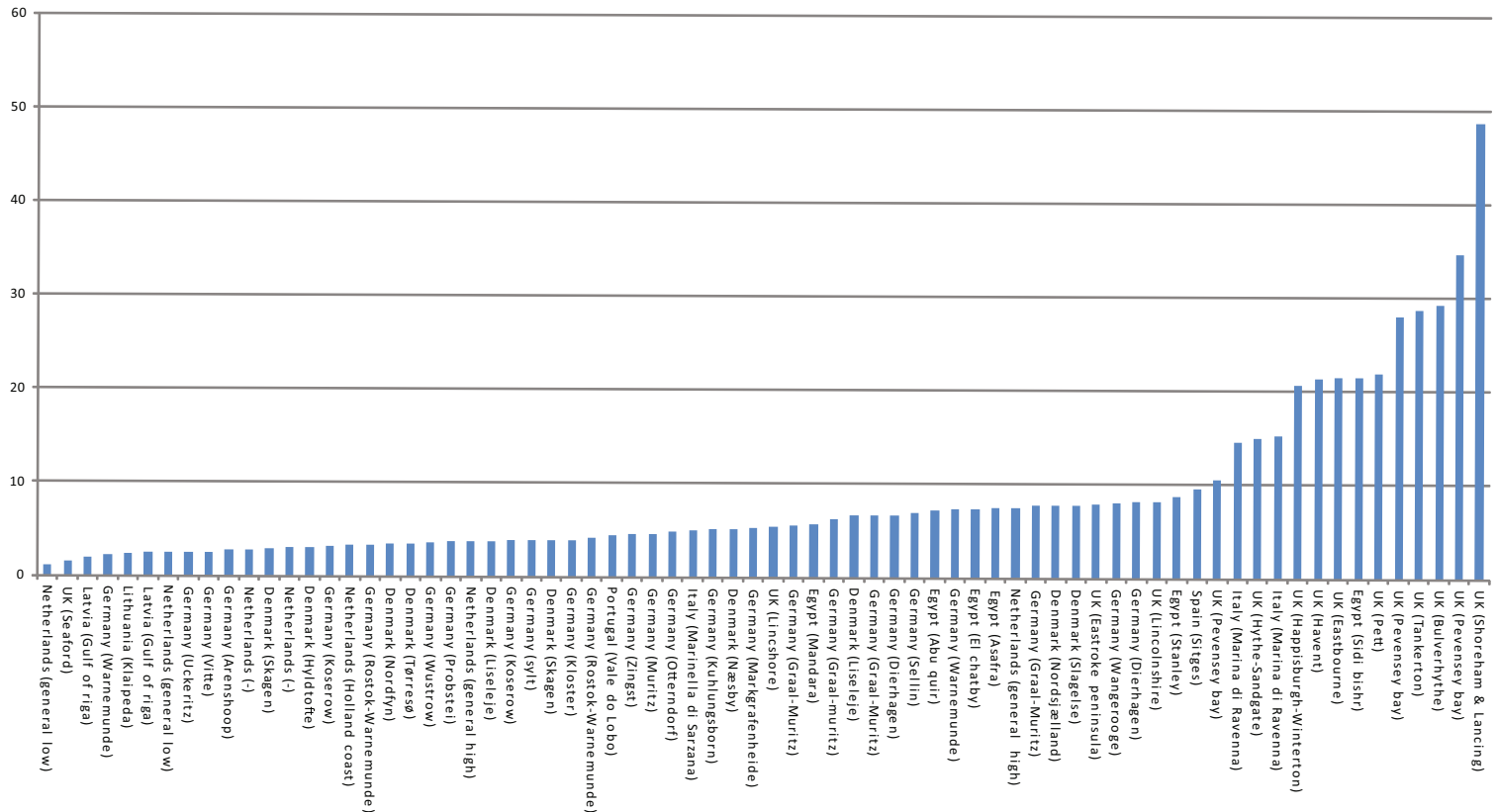

Fig. 8 Overview of beach nourishment costs in $€ / \mathrm{m}^{3}$ sand for a range of global projects over the last ca. 20 years (COWI 2009b; Dornbusch 2012; Dredging International 2012; El Raey et al. 1999; Environment Agency 2012, 2010; Evans 2012; Gabianelli 2004; Hillen et al 2010;

projects stay within the range of $1-10 € / \mathrm{m}^{3}$ sand, although the cost of some projects are significantly higher.

To be able to estimate the cost of a beach nourishment scheme for a particular coastline it is necessary to have more detailed information of the cost components that make up the price levels shown in Fig. 8. Therefore data has been collected of the approximate cost of the different project components from the two dredging companies Boskalis and Van Oord. Table 3 provides an overview of the magnitude of the different cost components in 2012 for projects carried out by the dredging company Boskalis. The table includes two different cost examples, where the beach nourishment is carried out by a small and large hopper dredger, and realistic numbers for mobilization costs, operation costs, sailing distance and sailing speed have been listed and used to calculate realistic examples of nourishment costs. The examples of the total cost in $€ / \mathrm{m}^{3}$ sand are shown without including the mobilisation cost, as the project size has a major influence on the mobilization cost $/ \mathrm{m}^{3}$ sand. It should be noted that these numbers only provides an indicative example of the magnitude of cost and the costs may increase by $10-50 \%$ for areas with high business risks such as developing countries. Also, mobilisation costs may be significantly higher for developing countries.

Table 4 shows the magnitude of costs for beach nourishment in 2012 for projects carried out by the dredging company Van Oord. Here, different cost examples are provided depending on the geographical conditions and project size. It should be noted, however, that these cost numbers can vary
Kystdirektoratet 2001; Linham et al. 2010; Pelliccia 2004; Povilanskas 2004a, b; Serra Raventos 2004; Sistermans 2004; Sistermans and Nieuwenhuis 2004a, b, c; Slagelse Kommune 2009; Valoso Gomes and Taveira Pinto 2004)

significantly depending on local conditions. As can be seen from Tables 3 and 4, the cost levels for the two examples are of

Table 3 Realistic example of cost components for beach nourishment by Boskalis in 2012 prices (Paulsen 2012)

Cost of beach nourishment (Boskalis example)

Beach nourrishment with small hopper dredger $-1.000 \mathrm{~m}^{3}$ vessel

Mobilisation cost (assuming sailing distance 100.000 Euro of 1000 Nautical miles)

Operation cost

Assumed sailing distance between 100.000 Euro/week source and deposition site

Assumed vessel speed $15 \mathrm{~km}$

Daily sand transport with $4 \mathrm{~h}$ cycles (both ways) $6.000 \mathrm{~m}^{3} /$ day Weekly sand transport with 7 days operation $\quad 42.000 \mathrm{~m}^{3} /$ week

Approximate cost per $\mathrm{m}^{3}$ sand (without mobilisation costs)

Beach nourrishment with large hopper dredger- $10.000 \mathrm{~m}^{3}$ vessel

Mobilisation cost (assuming sailing distance of 1000 Nautical miles)

700.000 Euro

Operation cost

Assumed sailing distance between 700.000 Euro/week source and deposition site

Assumed vessel speed $15 \mathrm{~km}$

10 knots

Daily sand transport with $4 \mathrm{~h}$ cycles (both ways) $60.000 \mathrm{~m}^{3} /$ day Weekly sand transport with 7 days operation $\quad 420.000 \mathrm{~m}^{3} /$ week

Approximate cost per $\mathrm{m}^{3}$ sand $1,7 \mathrm{Euro} / \mathrm{m}^{3}$ 
Table 4 Realistic example for cost of beach nourishment by Van Oord in 2012 prices (Lindo 2012)

Cost for beach nourishment (Van Oord example)

$\begin{array}{ll}\text { Beach nourishment } & \\ \text { Cost in Europe based on sailing } & 5-6 \mathrm{Euro} / \mathrm{m}^{3} \\ \text { distance of ca. } 15 \mathrm{~km} & \\ \text { Cost for increasing sailing distance up } & 0,2 \mathrm{Euro} / \mathrm{m}^{3} / \mathrm{km} \\ \text { to extra } 25 \mathrm{~km} & \\ \text { For large projects in more remote locations } & 7-8 \mathrm{Euro} / \mathrm{m}^{3} \\ \quad \text { where dredgers are not nearby } & \\ \text { For small projects in more remote locations } & 30 \mathrm{Euro} / \mathrm{m}^{3} \\ \quad \text { where dredgers are not nearby } & \end{array}$

the same magnitude if the mobilization costs are included in the Boskalis example.

The cost of beach nourishment for a particular coastal site also strongly depends on the amounts of sand needed and the frequency of nourishments. This depends on several factors including beach profile, wave exposure and sediment balance and the appropriate material needs should be estimated on a case-by-case basis. In order to provide a rough indication of the magnitude of sand needed for different coastal environments, however, one can generally look at coastlines with different wave exposures and sediment deficits. For an exposed coastline, the magnitude of sand needed for an indicative example could be $100-200 \mathrm{~m}^{3} /$ meter beach, with a possible extended span of $50-1000 \mathrm{~m}^{3} /$ meter beach. If the sediment deficit is moderate, the nourishment could be carried out every second year, while it could be carried out annually in locations with a large sediment deficit. For a moderately exposed coastline, the magnitude of sand needed for an indicative example could be $20-50 \mathrm{~m}^{3} /$ meter beach, with nourishments carried out every third year in cases with moderate sediment deficits and every second year in cases with a large deficit (Paulsen 2012). It should be noted, however, that these amounts are purely indicative but may provide a general picture of the magnitude of material needs.

The costs of dune construction/stabilization and cliff stabilization are highly dependent on local conditions including labour costs and are therefore not described further in this section. If dune construction is carried out based on dredged sand, the cost for beach nourishment can be used to estimate the project costs.

Cost examples of accommodation approaches

The cost of accommodation approaches are highly location specific and therefore difficult to compare at global level. For restoration of coastal wetlands such as marshes and mangrove forests, Tri et al. (1998) has indentified the following parameters to determine the cost level.
- The type of wetland to be restored, expertise availability and chances of success

- The degree of wetland degradation and consequent restoration requirements

- The intended degree of restoration (e.g. depending on other land use activities such as industrial development/ urbanization)

- The land cost if land purchase is required to convert the wetlands

- The labour costs

- The transportation distance between seedling source and planting site

- The seedling mortality rate between collection and planting

- The cost of raising specific species in nurseries before transplantation because they cannot be directly planted on mudflats due to strong wind and wave forces

- The scale of post-implementation monitoring operations

Tri et al. provides a cost example for a mangrove restoration project in Vietnam, where the cost of planting new mangrove trees is calculated to the order of $€ 30 /$ per hectare of planted mangrove in 2009 prices, including planting, capital and recurrent costs and subsequent thinning (Linham and Nicholls 2010; Tri et al. 1998). Although this can only be considered an independent example, similar cost magnitudes may apply to equivalent ecosystems and development contexts. Cost estimates for the other accommodation approaches have not been included here.

\section{Conclusion}

This paper has presented an overview of the CHW system that can be used for applying the system for practical multi-hazard assessment $\&$ management. The procedures outlined in the paper should be applicable on virtually all coastlines globally and can be used to improve the decision-base for coastal planners in areas with limited data availability and institutional capacity. The system faces some challenges in relation to urban or heavily modified coastlines as some components of these coastlines fall outside the coastal classification system. However, it is to some extent possible to use the system to evaluate how different human alterations affect e.g. the geological layout, wave exposure and sediment balance and thereby the inherent hazard levels. If any of the hazard management options listed in section "Identification of hazard management options" has been implemented at a coastal site, it can be assumed that the hazards they primarily address are reduced. However, as the hazard reduction effect of the different management options strongly depends on their specific design, quality and implementation, it is not possible to determine the exact level of hazard reduction. For coastal multi-hazard 
assessments, it is therefore recommended to use the standard classification categories unless it is very clear which coastal classification parameter a specific management measure affects and that the measure is of permanent character. The intention of the management sections of this paper is therefore mainly to give an overview of the appropriate management measures for a particular coastline, their effect on the different hazard types and their approximate cost levels, and not to provide information of the exact level of hazard reduction of a particular measure. Because the overall goal of the CHW system is to provide a low-tech tool suited for hazard management in areas with limited data availability and institutional capacity, the system involves a trade-off between simplicity and accuracy. Hence, it is recommended to use the CHW system as a basic assessment and management tool that can be supplemented with more detailed data collection, modelling and engineering calculations in locations where it is considered appropriate.

Acknowledgments We would like to thank Jan Paulsen, Mark Lindo, Aart Kroon and Thomas Balstrøm for fruitful discussions and advice and assistance with data collection.

Open Access This article is distributed under the terms of the Creative Commons Attribution License which permits any use, distribution, and reproduction in any medium, provided the original author(s) and the source are credited.

\section{References}

Balstrøm T (2008) Adaptions of ArcGIS' Linear Referencing System to the Coastal Environment. Esri Users Conference Proceedings, San Diego, CA

Cipriani LE, Pranzini, E (2012) Personal communication

Cipriani LE (2004) Marina di Massa-Marina di Pisa, Toscana (Italy). Eurosion

Coastal Engineering Research Center (1984) Shoreline protection manual. US Army Corps of Engineers, Washington

COWI (2009a) Kystbeskyttelse ved Gedser Odde. Guldborgsund Kommune

COWI (2009b) Sandfodring på Nordkysten. Gribskov Kommune

Davis RA Jr, Fitzgerald DM (2004) Beaches and coasts. Blackwell Publishing

Davies JL (1980) Geographical variation to coastal development, 2nd Edition, Longman (Pearson Education Limited)

Dornbusch U (2012) Environment agency, personal communication

Dredging International (2012) Beach nourishment / replenishment, project note dredging international

El Raey M, Dewidar K, El Hattab M (1999) Adaptation to the impacts of sea level rise in Egypt. Clim Res 12:117-128

Environment Agency (2012) Personal communication

Environment Agency (2010) Flood risk management estimating guideupdate 2010. Environment Agency

Evans C (2012) Personal communication

Farrow B (2012) Personal communication

Gabianelli G (2004) Marina di Ravenna Lido Adrino (Italy). Eurosion

Haslett SK (2009) Coastal systems. Routledge
Hillen MM, Jonkman SN, Kanning W, Kok M, Geldenhuys MA, Stive MJF (2010) Coastal defence cost estimates case studies of the Netherlands. TU Delft, New Orleans

IPCC (2013) Summary for policymakers. In: Stocker TF, Qin D, Plattner G-K, Tignor M, Allen SK, Boschung J, Nauels A, Xia Y, Bex V, Midgley PM (eds) Climate change 2013: the physical science basis. Contribution of Working Group I to the Fifth Assessment Report of the Intergovernmental Panel on Climate Change. Cambridge University Press, Cambridge

IPCC (2007) Climate change 2007: impacts, adaptation and vulnerability. In: Parry ML, Canziani OF, Palutikof JP, van der Linden PJ, Hanson CE (eds) Contribution of the Working Group II to the Fourth Assessment Report of the Intergovernmental Panel on Climate Change. Cambridge University Press, Cambridge

Jayappa KS, Vijaya Kumar GT, Subrahmanya (2003) Influence of coastal structures on the beaches of Southern Karnataka, India. J Coast Res $9: 2$

Kystdirektoratet (2001) Fodring og bypass på indre kyster. Kystdirektoratet

Lindo MH (2012) Van Oord, personal communication

Linham MM, Green CH, Nicholls RJ (2010) Cost of adaptation to the effects of climate change in the world's large port cities. AVOID

Linham MM, Nicholls RJ (2010) Technologies for climate change adaptation - coastal erosion and flooding. UNEP Risoe Centre, Roskilde

Mangor K (2004) Shoreline management guidelines. DHI Water \& Environment, Hørsholm

Masselink G, Hughes MG (2003) Introduction to coastal processes and geomorphology. Oxford University Press

Paulsen J (2012/2013) Boskalis, personal communication

Pelliccia FA (2004) Marinella di Sarzana (Italy). Eurosion

Povilanskas R (2004a) Klaipeda (Lithuania). Erosion

Povilanskas R (2004b) Gulf of Riga (Latvia). Eurosion

Press F, Siever R (2001) Understanding earth. Freeman and Company

Ramieri E, Hartley A, Barbanti A, Santos FD, Gomes A, Hilden M, Laihonen P, Marinova N, Santini M (2011) Methods for assessing coastal vulnerability to climate change, European Environment Agency. European topic centre on climate change impacts, vulnerability and adaptation

Reefbase (2013) Reefbase - a global information system for coral reefs. UNEP-WCMC

Rosbæk M (2012) Slagelse Kommune, personal communication

Rosendahl Appelquist L and Balstrøm T (2015) Application of a new methodology for coastal multi-hazard-assessment on the state of Karnataka, India. J Environ Manag

Rosendahl Appelquist L, Balstrøm T (2014) Application of the Coastal Hazard Wheel methodology for coastal multi-hazard-assessment on the state of Djibouti. Clim Risk Manag

Rosendahl Appelquist L (2012) Generic framework for meso-scale assessment of climate change hazards in coastal environments. J Coastal Conserv

Schoeman PK (2004) Wadden Sea Islands (The Netherlands). Eurosion

Schwartz ML (2005) Encyclopaedia of coastal science. Springer

Serra Raventos J (2004) Sitges (Spain). Eurosion

Sistermans P (2004) South Downs Sussex County (United Kingdom). Eurosion

Sistermans P, Nieuwenhuis O (2004a) Holland Coast (The Netherlands). Eurosion

Sistermans P, Nieuwenhuis O (2004b) Isle of Sylt Isles ScheslwigHolstein (Germany). Eurosion

Sistermans P, Nieuwenhuis O (2004c) Rostok (Germany). Eurosion

Slagelse Kommune (2009) Kystplan 2009

Skaarup P (2004) Hyllingebjerg-Liseleje (Denmark). Eurosion

Spyropoulos K (2004) Lakkopetra (Greece). Eurosion

Stive MJF, Aarninkoff SGJ, Hamm L, Hanson H, Larson M, Wijnberg KM, Nicholls RJ, Capbianco M (2002) Variability of shore and shoreline evolution. Coast Eng 47:211-235 
Thieler ER, Willams J, Hammer-Klose E (2000) National assessment of

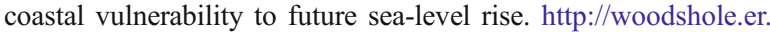
usgs.gov/project-pages/cvi/. Accessed online the 28 Nov 2011

Thisted Kommune (2008) Lild Strand Kystbeskyttelse. Thisted Kommune
Tri NH, Adger WN, Kelly PM (1998) Natural resource management in mitigating climate impacts: the example of mangrove restoration in Vietnam. Glob Environ Chang 8(1):49-61

Valoso Gomes F, Taveira Pinto F (2004) Vale do Lopo (Portugal). Eurosion 